\title{
An Analysis of the Risk of Transporting Uranium Ore Concentrates by Truck
}

\author{
C. A. Geffen
}

July 1981

Prepared for the U.S. Department of Energy under Contract DE-AC06-76RLO 1830

Pacific Northwest Laboratory Operated for the U.S. Department of Energy by Battelle Memorial Institute 
NOTICE

This report was prepared as an account of work sponsored by the United States Government. Neither the United States nor the Department of Energy, nor any of their employees, nor any of their contractors, subcontractors, or their employees, makes any warranty, express or implied, or assumes any legal liability or responsibility for the accuracy, completeness or usefulness of any information, apparatus, product or process disclosed, or represents that its use would not infringe privately owned rights.

The views, opinions and conclusions contained in this report are those of the contractor and do not necessarily represent those of the United States Government or the United States Department of Energy.

\author{
PACIFIC NORTHWEST LABORATORY \\ operated by \\ BATTELLE \\ for the \\ UNITED STATES DEPARTMENT OF ENERGY \\ Under Contract DE-AC06-76RLO 1830
}

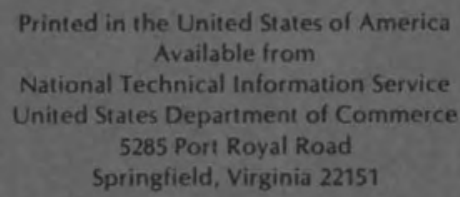

Price: Printed Copy \$ $\because$ Microfiche $\$ 3.00$

NTIS

-Pages Selling Price

001-025 $\$ 4.00$

026-050 $\$ 4.50$

$051-075 \quad \$ 5.25$

076-100 $\quad \$ 6.00$

101-125 \$6.50

126-150 \$7.25

$151-175 \quad \$ 8.00$

$176-200 \quad \$ 9.00$

$201-225 \quad \$ 9.25$

226-250 $\$ 99.50$

251-275 $\$ 10.75$

276-300 $\$ 11.00$ 
AN ANALYSIS OF THE RISK OF TRANSPORTING URANIUM ORE CONCENTRATES BY TRUCK

C. A. Geffen, Project Coordinator

Technical Contributors

J. M. Alzheimer

A. L. Franklin

J. R. Friley

C. A. Geffen

J. Mishima

B. A. Napier

J. M. Oylear

S. L. Sutter

Ju1y 1981

Prepared for

the U.S. Department of Energy

under Contract DE-AC06-76RLO 1830

Pacific Northwest Laboratory Richland, Washington 99352 


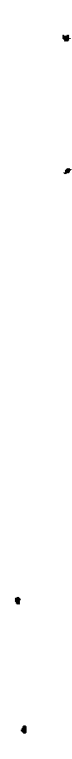




\section{PREFACE}

This study was initiated in FY79 in the Transportation Safety Studies Project performed at Pacific Northwest Laboratory (PNL) for DOE's Division of Environmental Control Technology. In FY80, responsibility for this work was transferred to the Division of Transportation and Fuel Storage and overview of the work was assigned to the Transportation Technology Center (TTC) at Sandia Laboratories, DOE's lead laboratory for Nuclear Materials Transportation Technology. This work was substantially complete when assigned to TTC overview and TTC funds were used only for incorporation of review comments and for publication. Funds for completion and publication of this study have been provided to PNL through TTC. 



\section{$\underline{\text { ABSTRACT }}$}

This report evaluates the risks involved with shipping uranium ore concentrates by truck in an attempt to provide some perspective on the system safety issues. The basic probabilistic risk evaluation methodology used in this study is similar to that employed by Pacific Northwest Laboratory (PNL) in a series of risk analyses on the transportation of potentially hazardous energy materials. The risk model has been constructed as a series of separate analysis steps to allow the system risk to be readily reevaluated as additional data become available or as postulated system characteristics change.

The results of this analysis show that the risks to the public health and safety from yellowcake releases during a transportation accident are insignificant. Accidents involving truck shipments of yellowcake are expected to occur at a rate of about ten a year. However, only one-fifth of these accidents, or about two a year, are expected to cause a release of yellowcake to the environment. None of these accidents was estimated to produce any potential fatalities. The low concentration of radioactivity distributed throughout the material resulted in no significant increase in radiation doses above normal background levels to members of the general public. 


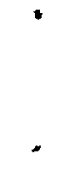




\section{CONTENTS}

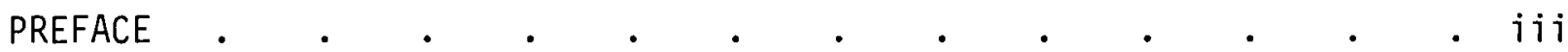

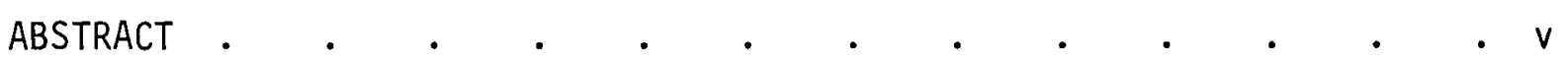

1.0 SUMMARY $\quad . \quad$.

2.0 INTRODUCTION

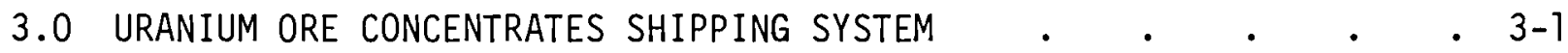

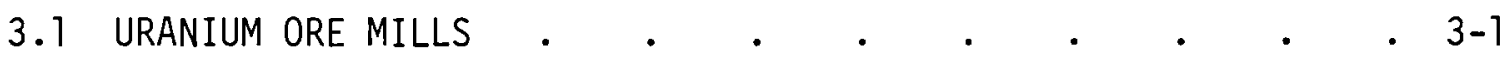

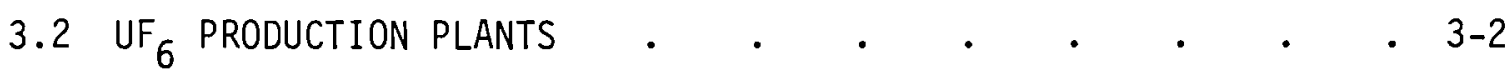

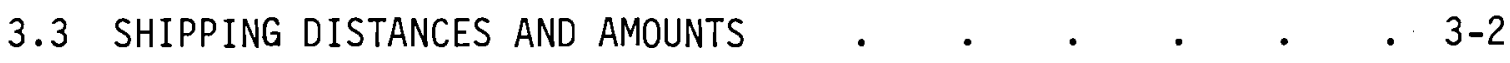

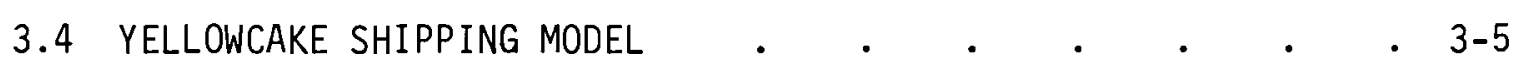

4.0 RELEASE SEQUENCE IDENTIFICATION AND EVALUATION $\quad$ • • • • •

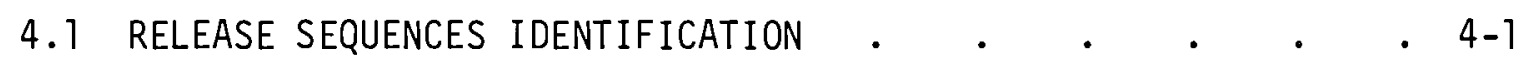

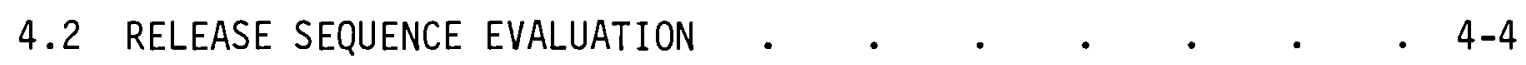

4.2.1 Basic Event Probabilities . . . . . . . 4-4

4.2.2 Release Fractions . . . . . . . . . . 4-7

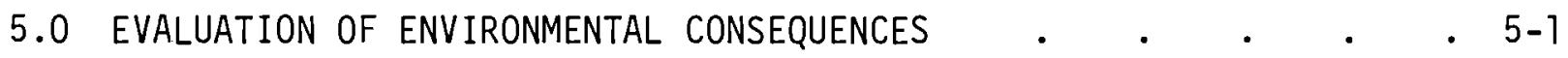

5.1 HEALTH EFFECTS . . . . . . . . . . $5-1$

5.2 METEOROLOGY . . . . . . . . . . . . $5-5$

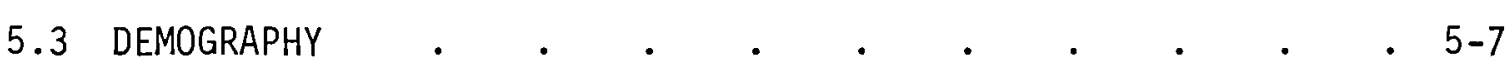

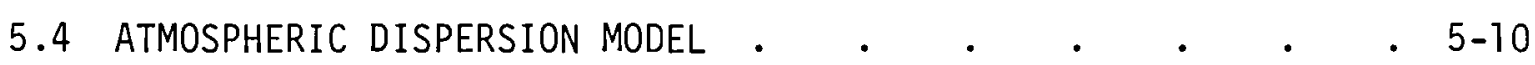

6.0 THE RISK OF SHIPPING URANIUM ORE CONCENTRATES BY TRUCK • • • •

6.1 RISK EVALUATION OF URANIUM ORE CONCENTRATE SHIPMENTS 6-2

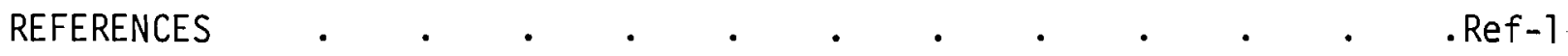
APPENDIX A - TRANSPORTATION RISK ANALYSIS METHODOLOGY • . . • . A-1 APPENDIX B - URANIUM ORE CONCENTRATE SHIPPING SYSTEM DESCRIPTION • • • B-1 APPENDIX C - RELEASE SEQUENCE PROBABILITIES • • • • • • • $\quad$ C-1 APPENDIX D - ESTIMATED AIRBORNE RELEASE FRACTIONS • • • • • • • D-1 


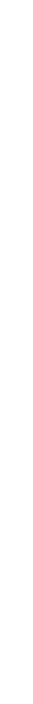


$\underline{\text { FIGURES }}$

3.1 Origins, Destinations and Shipment Routes for Uranium Ore Concentrate Shipments . $\quad . \quad$. $\quad . \quad$. $\quad$. 3-4

4.1 Yellowcake Transportation Fault Tree . . . . . . 4-2

5.1 Population Zones and Yellowcake Shipping and Receiving

Facilities . . . . . . . . . . . 5-8

A.1 Model to Calculate the Risk of Shipping Energy Materials - A-2

B.1 Department of Transportation Specification $17 \mathrm{H}$ Steel Drum . B-2

B.2 Configuration of Drums in Semi-Trailer . . . . . . B-2

B.3 Yellowcake Particle Size Distribution . . . . . . B-4

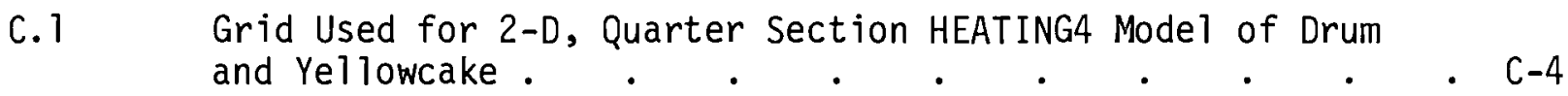

C.2 Temperature Response of Yellowcake Drum . . . . . . C -4

C.3 Temperature Dependent Tensile and Yield Strength of Low

C.4 Crush Force Versus Displacement $\quad$ - . . . . . . . . . C-9

C.5 Dynamic Finite Element Predictions of Drum Crush for $2.3 \mathrm{~g}$

C.6 Drum Failures Versus Trailer Deceleration . . . . . C-10

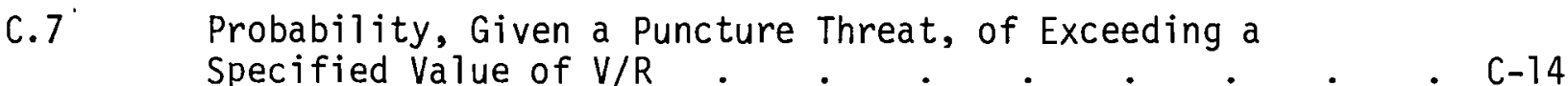

C.8 Probability of Immersion at Depth Greater Than That Shown,
Given Immersion . . . . . . . . . . c-15

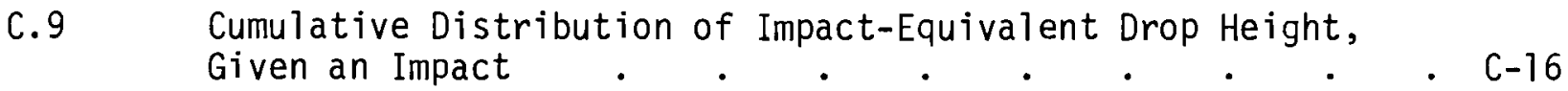

C.10 Cumulative Distribution of Crush Forces Showing Probability of Encountering a Crush Environment More Severe Than Chosen

Force if a Collision Occurs . . . . . . . C C-17

D.1 Fraction of Source Potentially Airborne as a Function of Wind Speed $1 \mathrm{mph}=0.447 \mathrm{~m} / \mathrm{sec} \quad . \quad$. $\quad . \quad . \quad . \quad$. $0-1$

Draction of Mass Resuspended from Two Surfaces, Freshly
Dispersed $\mathrm{UO}_{2}, 24$-Hour Period Following Dispersal . . . D-3 


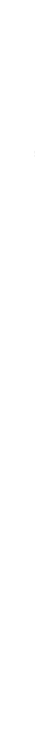




\section{$\underline{\text { TABLES }}$}

1.1 Summary of Uranium Ore Concentrates Shipping System . . 1-2

3.1 Shipping Distances $(\mathrm{km})$. $\quad$. $\quad . \quad$. . . . . $3-3$

3.2 Projected Yellowcake Shipments for mid-1980s . . . . 3-3

4.1 Fault Tree Symbolism . . . . . . . . 4-3

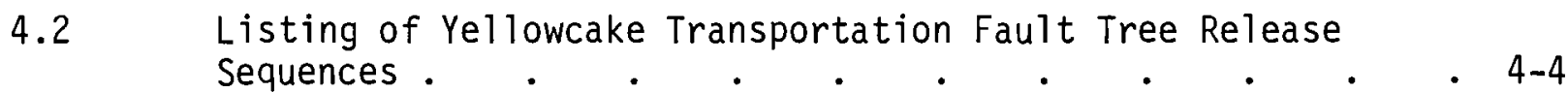

4.3 Release Sequences and Probabilities for Uranium Ore

4.4 Estimated Release Quantities for Impact and Crush Accidents . 4-9

5.1 Isotopic Composition of Yellowcake . . . . . . 5-2

5.2 Dose to Critical Organ Via Inhalation of Uranium Compounds . 5-3

5.3 Health Effects Conversion Factors-Population Dose to Maximum Number of Health Effects . . . . . . . . 5-4

5.4 Assumed Limits and Chemical Health Effects of the Inhalation of Uranium . . . . . . . . . 5-4

5.5 Average Wind Speed/Stability Characteristics . . . . 5-6

5.6 Projected Population Density and Land Area by Zone and

Population Classes . . . . . . . . . 5-7

5.7 Yellowcake Shipment Origins and Destinations . . . . 5-9

5.8 Fractional Mileage of Shipping Routes by Population Zone . 5-9

5.9 Fractional Mileage of Shipping Routes by Population Zones

6.1 Simplified Uranium Ore Concentrates Shipping System Model • 6-2

B.2 Yellowcake Particle Size Distribution . . . . . B-4

D.1 Fraction of Source Potentially Airborne . . . . . D-2

D.2 Fraction of Mass Resuspended from a Surface, Freshly Dispersed $\mathrm{UO}_{2}$ 24-Hour Period Following Dispersion . . . . . . D-4

D.3 Release Fraction Calculations for Impact Accident . • • D-5

D.4 Release Fraction Calculations for Crush Accident . . • D-6 


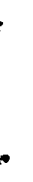




\subsection{SUMMARY}

The safety of nuclear material transportation systems has long been a public concern. A recent series of accidents involving the transportation of uranium ore concentrates (also known as yellowcake) by truck have focused attention on the safety of the shipping system for this radioactive material. This report evaluates the risks involved with shipping uranium ore concentrates in an attempt to provide some perspective on the system safety issues. It is the ninth in a series of risk analyses performed by the Pacific Northwest Laboratory (PNL) on the transportation of potentially hazardous energy materials. (a) The basic risk evaluation methodology used in this study was developed in the first report of this series (McSweeney 1975), and is summarized in Appendix A. The risk evaluation model has been constructed as a series of separate analysis steps to allow the risk to be readily reevaluated as additional data become available or as postulated system characteristics change.

Four basic steps are followed in the PNL transportation risk evaluation methodology to develop the information required to perform the risk analysis. These four steps are:

- A detailed description of the transportation system, including projected industry characteristics, size and number of shipments, and material characteristics.

- The identification of possible material release sequences, using fault tree analysis.

- The evaluation of the probabilities and consequences of releases, using container failure data and mathematical models that express dispersion and health effects.

- The calculation and evaluation of risk, defined as the product of the probability of a release of material to the environment and the consequences of that release.

(a) The other studies include McSweeney 1975, McSweeney 1977, Hal1 1977, Geffen 1978, Elder 1978, Rhoads 1978, Geffen 1980, and Andrews 1980. 
The report is sectioned to correspond to specific analysis steps identified in the risk evaluation methodology. The transportation system is described in Section 3. Release sequences are postulated and evaluated in Section 4. The possible consequences of each release seçuence are discussed in Section 5, while the shipping system risk is presented in Section 6 . Supportive data and analyses are given in the appendices.

The risk evaluation results are related to industry conditions expected to exist in the mid-to-late 1980s to allow a comparison with other reports in this series. Certain assumptions about the uranium shipping industry were made for the purposes of this assessment. These assumptions included the following:

- Shipping systems and basic distribution patterns are the same as in the mid-1970s.

- All uranium ore concentrate or yellowcake shipments are made by truck.

- The total amount of yellowcake shipped corresponds to that necessary to support a nuclear industry with an installed generating capacity of $100 \mathrm{GW}$ of electric power.

The shipping system description developed from these assumptions is summarized in Table 1.1.

TABLE 1.1. Summary of Uranium Ore Concentrates Shipping System

\begin{tabular}{|c|c|c|c|c|c|c|c|}
\hline $\begin{array}{l}\text { Shipping } \\
\text { Container }\end{array}$ & $\begin{array}{l}\text { Transport } \\
\text { Mode } \\
\end{array}$ & $\begin{array}{c}\text { Amount/ } \\
\text { Container (MT) }\end{array}$ & $\begin{array}{l}\text { Containers/ } \\
\text { Shipment }\end{array}$ & $\begin{array}{l}\text { Material } \\
\text { Shipped/ } \\
\text { Year (MT) }\end{array}$ & $\begin{array}{l}\text { Number of } \\
\text { Shipments/ } \\
\text { Year }\end{array}$ & $\begin{array}{c}\text { Average } \\
\text { Shipment } \\
\text { Distance }(\mathrm{km})\end{array}$ & $\begin{array}{c}\text { Accident/ } \\
\mathrm{km}\end{array}$ \\
\hline 55-gal drum & Truck & 0.36 & 50 & 45,700 & 2544 & 2660 & $1.55 \times 10^{-6}$ \\
\hline
\end{tabular}

The results of this analysis show that the risks to the public health and safety from yellowcake releases during a transportation accident are insignificant. Based on the information in Table 1.1, accidents involving truck shipments of yellowcake would be expected to occur at a rate of about ten a year. However, the results of this analysis show that only one-fifth of these accidents, or about two a year, are expected to cause a release of yellowcake to the environment. None of these accidents was estimated to produce any potential fatalities. 
In this study, the chemical toxicity of yellowcake, rather than its radiological properties, was found to be the primary potential cause of fatalities. Based on the chemical health effects of a yellowcake release, a level of $100 \mathrm{mg}$ of soluble uranium must be inhaled and dissolved in the blood to cause fatal health effects. The minimum concentration of yellowcake in air necessary to achieve this condition was found to be about $60 \mathrm{mg} / \mathrm{m}^{3}$. However, a person would have to be continuously exposed to this concentration for more than 24 hours to experience any potential fatal health effects.

The physical characteristics of yellowcake make it very difficult to meet these conditions. Most yellowcake particles that are inhaled are trapped in and expelled by nose and throat passageways. Also, yellowcake is difficult to disperse, and does not ma intain suspension in air for long periods of time (usually less than 10 to 15 minutes for high concentrations of the material).

Thus, the results of this study show that there are no expected fatalities from inhaling yellowcake released as a result of transportation accidents. The potential for radiation or other injuries was not estimated in this study. However, the low concentration of radioactivity distributed throughout the material generally resulted in no significant increase in radiation doses above normal background levels to members of the general public. 



\subsection{INTRODUCTION}

The nuclear fuel cycle begins with the mining and milling of natural uranium ore to a concentrate containing about $80 \%$ uranium oxide $\left(\mathrm{U}_{3} \mathrm{O}_{8}\right)$. The concentrate is then purified and converted to uranium hexafluoride $\left(\mathrm{UF}_{6}\right)$, which, after enrichment, is used to manufacture reactor fuel elements. The uranium concentrate, more commonly known as yellowcake, is transported by truck in 210 \& (55-gallon) drums from the mills to the conversion plants.

The safety record for shipping yellowcake has been excellent. No deaths or significant injury to persons as a result of shipment radioactivity have been experienced, even in the unusual occurrence of a material release during a transportation accident. However, recent accidents involving truck shipments of uranium ore concentrates have focused public attention on the safety of these operations. For example, a 1977 truck accident in Colorado, in which several tons of yellowcake were spilled on the ground, prompted a review by the Nuclear Regulatory Commission (NRC) and the Department of Transportation (DOT) of the regulations and practices related to the transportation of yellowcake and other radioactive materials.

This report attempts to place the issue of uranium ore concentrate shipments in better perspective by analyzing the risks involved in shipping these materials by truck. Risk, as used in the context of this report, includes a consideration of both the probability of a release of material to the environment and the consequences resulting from the release. An analysis of risk enables the consequences of postulated releases of energy materials during transport to be put into perspective by viewing the events relative to their expected frequency of occurrence.

This study was part of a program on transportation safety that was conducted by Pacific Northwest Laboratory (PNL) for the Department of Energy's Division of Environmental Control Technology. The objective of the program was to develop a methodology for quantitatively analyzing the safety of transporting energy materials and to apply this methodology to current and future shipping systems. Risk analysis was the technique selected for this evaluation. 
Four basic steps are followed in the PNL transportation risk evaluation methodology to develop the information required to perform the risk analysis. These four steps are:

- A detailed description of the transportation system, including projected industry characteristics, size and number of shipments, and material characteristics.

- The identification of possible material release sequences, using fault tree analysis, and an evaluation of the probabilities of those release sequences occurring using container failure data.

- The evaluation of the consequences of releases, using mathematical models that express dispersion and health effects.

- The calculation and evaluation of risk, defined as the product of the probability of a release of material to the environment and the consequences of that release.

A more detailed discussion of the methodology is presented in Appendix A.

The risk methodology used in this report was initially applied to the shipment of plutonium by truck (McSweeney 1975) and has subsequently been applied to the shipment of plutonium by train (Hall 1977) and air (McSweeney 1977); the shipment of uranium hexafluoride by truck and train (Geffen 1978); the shipment of gasoline by truck (Rhoads 1978); the shipment of spent fuel by truck (Elder 1978); the shipment of propane by truck and train (Geffen 1980); and the shipment of chlorine by train (Andrews 1980). This report presents the results of an analysis of the risk of transporting uranium ore concentrates by truck. These results show the risks to the public to be very low. However, to provide consistency with other reports in this series, a detailed analysis of the system was performed. The information contained in this detailed report is expected to be of value to shippers of uranium ore concentrates and decision makers in addressing system safety issues.

The uranium ore concentrates shipping system is presented in Section 3. Material release sequences are identified and evaluated in Section 4 of this report. Potential consequences of a material release are discussed in Section 5. 
The analysis of the risk of transporting uranium ore concentrates by truck is presented in Section 6. Supportive data and analyses, as well as a detailed presentation of the PNL risk analysis methodology, are given in the appendices. 



\subsection{URANIUM ORE CONCENTRATES SHIPPING SYSTEM}

This risk analysis is based on a specific set of assumed shipping requirements. These include the projected amount of material to be shipped and the number, origin, and destination of the shipments. The reference time frame considered in this study is in the mid-1980s, when a total installed nuclear electric generating capacity of 100 Gigawatts is expected to be operating in the U.S. This basis was chosen to allow comparisons with relative risks involved in shipping other nuclear fuel cycle materials as determined in earlier studies (McSweeney 1975; Hall 1977; McSweeney 1977; Geffen 1978; and Elder 1978).

\subsection{URANIUM ORE MILLS}

In the milling operation, uranium is extracted from the uranium ore and is concentrated into a semi-refined product, commonly called "yellowcake." This resultant uranium concentrate is a powder, usually canary-yellow in color. Because the concentrate consists of a variety of compounds, yellowcake is generally specified in terms of its $\mathrm{U}_{3}{ }_{8}$ content, which is usually around 80 percent.

The projected total amount of $\mathrm{U}_{3} \mathrm{O}_{8}$ to be required in the mid-1980s is about 36,560 metric tons (MT) (Nuclear Fuel 1977). Assuming an average $\mathrm{U}_{3} \mathrm{O}_{8}$ content of 80 percent, this represents 45,700 MT of yellowcake. About $87 \%$ of this total has historically been supplied by domestic mills. The remainder has been imported from foreign sources (Kahn 1978). This trend is assumed to be applicable to the reference time frame for the purposes of this study. Thus, 39,690 MT is assumed to be obtained from domestic mills. The remaining amount (6010 MT) is assumed to be imported from foreign sources.

As of 1977, there were 32 separate facilities in the U.S. either operating or planning to produce yellowcake (Jimison 1977). These mills are primarily located in New Mexico, Wyoming, and Colorado, with the remainder situated in Texas, Utah, South Dakota, and Washington. For the purpose of this analysis, the uranium mills have been classified by general geographic area. The representative locations are: 
- Canon City, Colorado

- Casper, Wyoming

- Falls City, Texas

- Ford, Washington

- Grants, New Mexico

- Moab, Utah.

\section{$3.2 \underline{U F}_{6}$ PRODUCTION PLANTS}

From the uranium milling plant, yellowcake is shipped to a conversion facility where it is converted to a gaseous compound, uranium hexafluoride $\left(\mathrm{UF}_{6}\right)$, that can be used in the uranium enrichment step of the nuclear fuel cycle. There are currently two $\mathrm{UF}_{6}$ production plants operating in the U.S., located at Metropolis, Illinois, and Sequoyah, Oklahoma. These are assumed to be the same as those that will be operating in the reference year.

\subsection{SHIPPING DISTANCES AND AMOUNTS}

Shipping distances between various facilities are shown in Table 3.1. The amounts shipped, based on current industry characteristics, are summarized in Table 3.2. For this analysis, current distribution patterns were assumed. Thus, 80 percent of al1 foreign material originated in Canada and was assumed to enter the U.S. at Chicago. The remaining 20 percent, from other foreign sources, is assumed to enter the U.S. through the ports of Baltimore, Maryland, and Norfolk, Virginia (Kahn 1978). The various origins and destinations for yellowcake shipments are shown in Figure 3.1. The relative contributions of each mill to total yellowcake production is based on current milling capacities, obtained from Coleman 1978. The percentage of yellowcake shipped from each mil1 to $\mathrm{UF}_{6}$ production plants is based on 1975 shipping patterns, obtained from Jimison 1977. The average shipping distance for a uranium ore concentrate shipment is $2660 \mathrm{~km}$, found by taking the average of the shipping distances between each origin-destination pair, weighted by the number of shipments along that route.

Currently, about 6 percent of the available domestic supply is slated for foreign use by sales commitment. This trend, however, is projected to decrease 
TABLE 3.1. Shipping Distances (km)

\begin{tabular}{|c|c|c|}
\hline From & $\begin{array}{l}\text { To UFG Produ } \\
\text { Metropolis, } \\
\text { Illinois } \\
\end{array}$ & $\begin{array}{l}\text { ion Plants } \\
\text { Sequoyah, } \\
\text { Oklahoma }\end{array}$ \\
\hline \multicolumn{3}{|l|}{ Domestic Sources } \\
\hline Canon City, Colorado & 1660 & $--(a)$ \\
\hline Casper, Wyoming & 1980 & 1610 \\
\hline Falls City, Texas & 1460 & 1000 \\
\hline Ford, Washington & $--(a)$ & 2930 \\
\hline Grants, New Mexico & 1930 & 1170 \\
\hline Moab, Utah & 2080 & $\ldots(a)$ \\
\hline \multicolumn{3}{|l|}{ Foreign Sources } \\
\hline Baltimore, Maryland & 1260 & $--(a)$ \\
\hline Chicago, Illinois & 560 & 1290 \\
\hline Norfolk, Virginia & 1240 & $--(a)$ \\
\hline
\end{tabular}

(a) No shipments are projected between these locations, according to 1975 shipping patterns.

TABLE 3.2. Projected Yellowcake Shipments for mid-1980s

From

Domestic Sources

Canon City, Colorado

Casper, Wyoming

Falls City, Texas

Ford, Washington

Grants, New Mexico

Moab, Utah

Foreign Sources

Baltimore, Maryland

Chicago, Illinois

Norfolk, Virginia
To UF Production Plants

\begin{tabular}{lll}
\hline Metropolis, I17 Number of & Sequoyah, Oklahoma \\
Amount (MT) Shipments & Amount (MT) Shipmer of \\
Shists
\end{tabular}

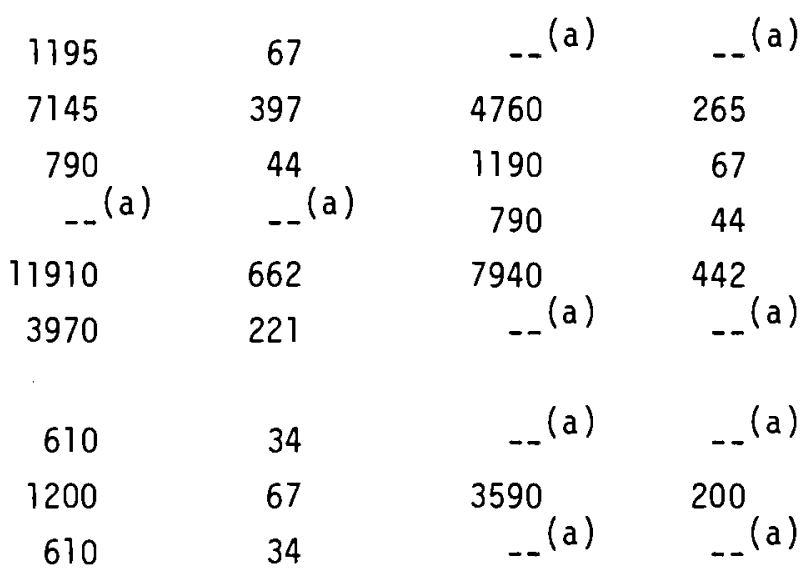

(a) No shipments are projected between these locations according to 1975 shipping patterns. 


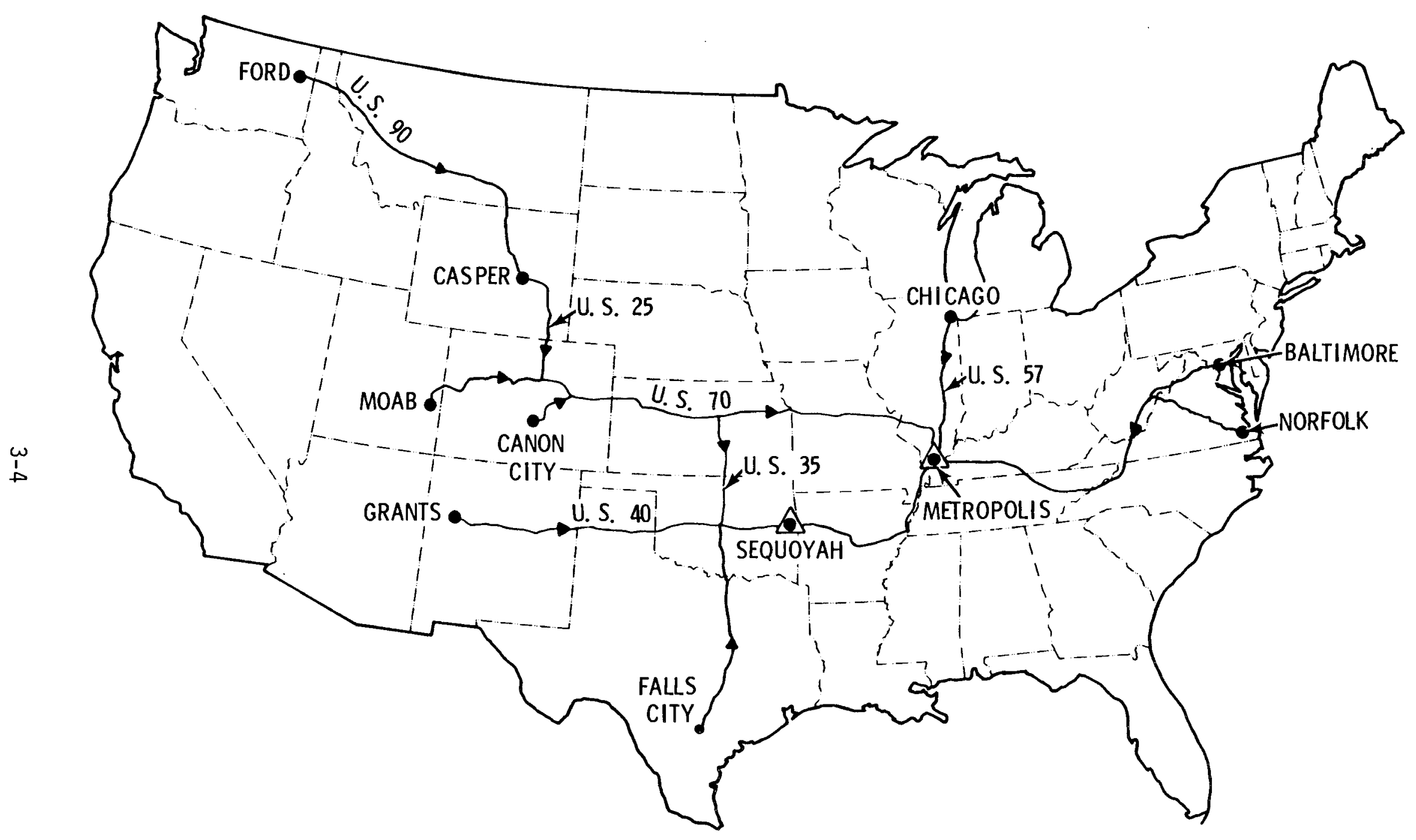

FIGURE 3.1. Origins, Destinations and Shipment Routes for Uranium Ore Concentrate Shipments 
to about 1 percent by 1985 (U.S. DOE 1978). Since these exports are postulated to be minimal, export shipments of $\mathrm{U}_{3} \mathrm{O}_{8}$ are not addressed in this study.

\subsection{YELLOWCAKE SHIPPING MODEL}

Yellowcake is classified as low specific activity (LSA) material according to the Department of Transportation Hazardous Materials Regulations and is transported in 210 liter (55-gal1on) steel drums. The typical drum has a yellowcake capacity of $360 \mathrm{~kg}$ (800 pounds), though this may vary from shipment to shipment depending on the moisture content of the concentrate. Detailed information on the yellowcake containers and material properties is presented in Appendix B.

According to industry sources, most yellowcake is transported by truck in an enclosed trailer. For the purpose of this study, all of the shipments of yellowcake are assumed to be moved by truck. In genera1, 50 drums may be packed in one truck shipment without exceeding current weight limitations for highway transport. This results in a net cargo weight of about 18 MT per shipment. Based on these assumptions, the number of shipments required for the yellowcake shipping model are shown in Table 3.2. 



\subsection{RELEASE SEQUENCE IDENTIFICATION AND EVALUATION}

This section presents an identification and evaluation of potential release sequences for the yellowcake shipping system. The information discussed below is used in calculating the probability component of risk, in terms of the expected frequency of occurrence of a particular release type. The consequences of these releases, in terms of health effects, will be discussed in Section 5 . These components of risk will be combined in Section 6 .

\subsection{RELEASE SEQUENCES IDENTIFICATION}

Several transportation accidents involving the shipment of uranium ore concentrates have occurred in the past. However, the statistical information available from state and federal agencies does not provide a sufficient basis to identify all the mechanisms by which the containers may potentially fail. A complete scenario of the possible ways that releases could occur (release sequences) must be identified by a reasoning process.

The procedure used in this study for identifying combinations of conditions that could result in a release of yellowcake to the environment is fault tree analysis. This technique is discussed further in Appendix A. The methodology involves first the postulation of a release of material during transport and then the examination of the series of events that must have occurred to cause the release. This form of reasoning is thought to be more inclusive than beginning with an initiating event and working toward defining a release (i.e., constructing accident scenarios or event trees). The fault tree that is developed is then broken down into all the possible release sequences. In theory, a 11 the accident scenarios can be obtained from the fault tree. When properly applied, the accident scenarios obtained from using the fault tree methodology are likely to be more complete than the alternative method of trying to list all accident scenarios without the aid of any formalized reasoning process. The tree constructed using the fault tree methodology is used as the basis for estimating the total release probability.

The fault tree for shipment of uranium ore concentrates by truck was developed for normal truck transport on primary highways in the United States. The 
effects of sabotage or natural disasters on material shipments were not included in this analysis. The analysis does not address loading and unloading accidents or the combined effects of the accident environment and packaging condition. Previous analyses have shown that packaging condition has only minor effects on risk (Hall 1977, Geffen 1978, Elder 1978).

The simplified fault tree developed for the shipment of yellowcake is shown in Figure 4.1. The top event of the tree is the postulated release of yellowcake to the environment during transportation accidents. The fault tree was constructed by drawing a separate branch to analyze the failure of the yellowcake containers by each type of accident force - fire, impact, crush, puncture and immersion - that was likely to be encountered in a transportation accident. Each of the significant fault tree branches was then further broken down to basic events that can be assigned failure probabilities. Identified events or failure elements used in the fault tree that could contribute to a release are designated in the fault tree as " $X$ " with associated numerical designations and

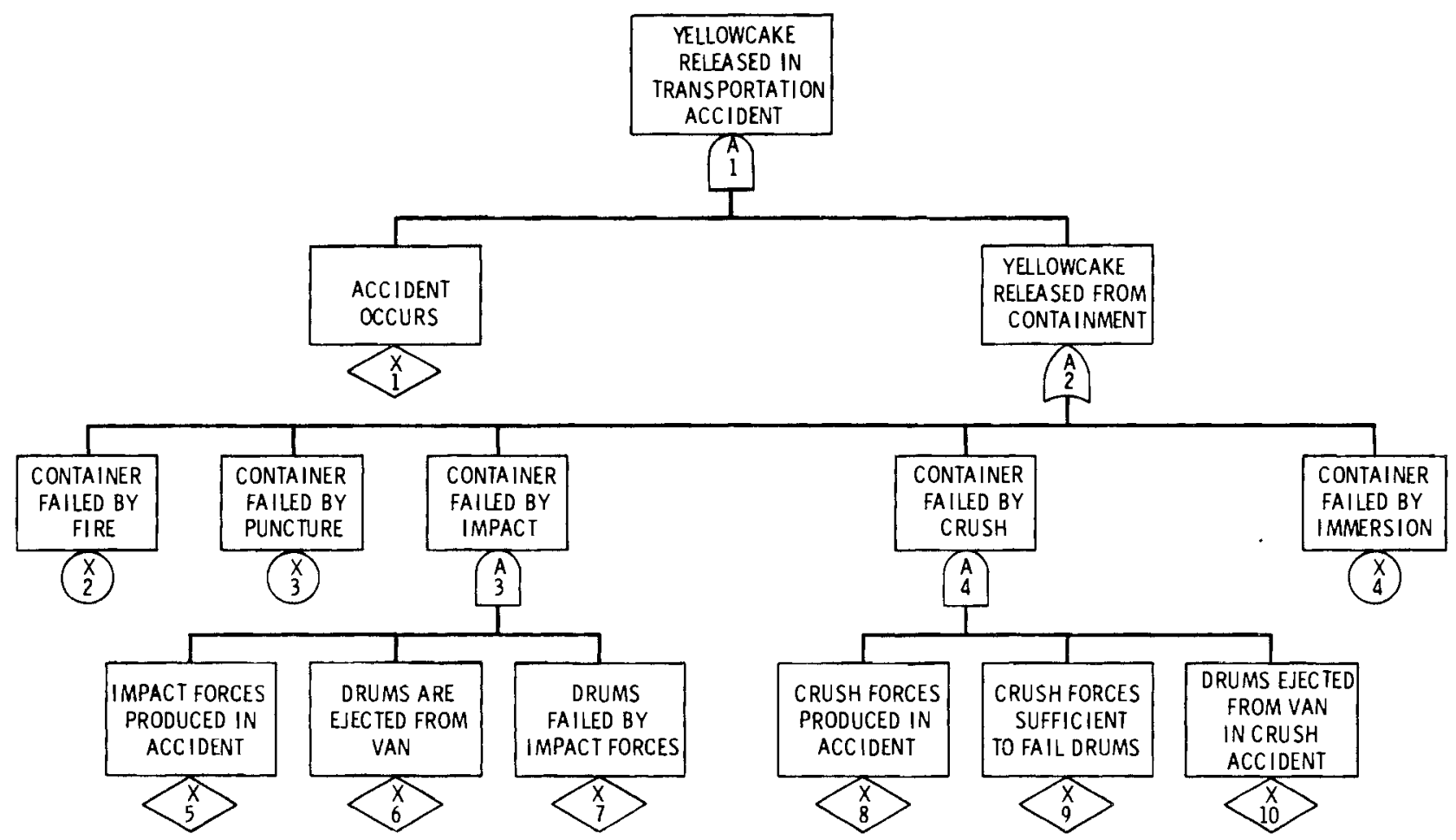

FIGURE 4.1. Yellowcake Transportation Fault Tree 
descriptive titles. Elements that have been further developed in the fault tree are designated by "A". Table 4.1 gives the various fault tree symbols and their meanings. A listing of the release sequences identified from the yellowcake transportation fault tree is presented in Table 4.2.

TABLE 4.1. Fault Tree Symbolism

SYMBOL

MEANING AND USE

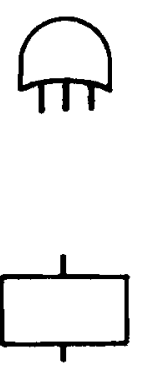

OUTPUT INPUTS

"AND" LOGIC GATE. THE SIMULTANEOUS OCCURRENCE OF INPUTS IS REQUIRED TO CAUSE AN OUTPUT.

OUTPUT "OR" LOGIC GATE THE OCCURRENCE OF ANY ONE OF THE INPUTS INPUTS WILL RESULT IN AN OUTPUT.

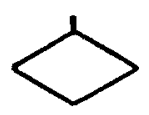

FAULT EVENT THAT RESULTS FROM THE LOGICAL OPERATION OF TWO OR MORE FAULT EVENTS. IT IS ALWAYS THE OUTPUT FROM A LOGIC GATE.

INFERRED FAULT EVENT. ANY FAILURE EXCEPT A PRIMARY FAILURE WHICH IS NOT DEVELOPED FURTHER DUE TO LACK OF INFORMATION, TIME OR MONEY OR DUE TO THE LOW PROBABILITY OF OCCURRENCE. IT CAN ALSO BE USED WHERE OTHER ANALYSES GIVE SUFFICIENT INFORMATION TO INDICATE THAT FURTHER ANALYSIS WOULD BE REDUNDANT.

BASIC FAULT EVENTS THAT ARE FOUND DURING ANALYSIS TO BE HIGHLY IMPROBABLE OCCURRENCES OR TO CONTRIBUTE INSIGNIFICANTLY TO OVERALL SYSTEM RISK. THESE EVENTS ARE NOT FURTHER DEVELOPED WITHIN THE TREE, AND ARE INCLUDED ONLY FOR COMPLETENESS. 
TABLE 4.2. Listing of Yellowcake Transportation Fault Tree Release Sequences

\begin{tabular}{|c|c|c|c|}
\hline $\mathrm{X} 1$ & & & (Container Failed by Fire) \\
\hline$x 3$ & & & (Container Failed by Puncture Forces) \\
\hline$x 4$ & & & (Container Failed by Immersion Forces) \\
\hline$\times 5$ & $\times 6$ & $x 7$ & (Container Failed by Impact Forces) \\
\hline$x 8$ & $\times 9$ & $\times 10$ & (Container Failed by Crush Forces) \\
\hline
\end{tabular}

\subsection{RELEASE SEQUENCE EVALUATION}

The previous section presented the simplified fault tree and release sequences for the shipment of uranium ore concentrates by truck. The frequency of occurrence and the amount of material released (release fraction) must now be determined for each release sequence. Estimation of release sequence probabilities primarily requires knowledge of the forces or stresses that may be generated in a truck accident, and the level of applied stress to a container that will result in container failure and a release of material to the environment. The estimated basic event probabilities used in this analysis are presented in Section 4.2.1. The individual event probabilities are then used to develop information on release sequence probabilities. Release fractions are evaluated in Section 4.2.2.

\subsubsection{Basic Event Probabilities}

The following paragraphs provide a sequential description of failure probability estimates for basic events in the yellowcake transportation fault tree that could contribute to a release during the shipment of uranium ore concentrates by truck. Failure of a container during an accident occurs when the forces generated exceed the mechanical strength of the container affected. For this analysis, the stresses present in a truck accident include fire, puncture, immersion, impact and crush. Information on accident environments was developed by Sandia Laboratories (Clarke 1976), and is presented with information on container strength obtained from structural analysis, detailed in Appendix $C$.

The expected frequency of each release sequence developed in the fault tree is obtained by taking the product of the probability of each event in the 
sequence. The estimates of the basic event probabilities are presented below. The detailed derivation of these values is discussed in Appendix $C$. These values refer to the probability of failing at least one yellowcake drum. The number of failed drums involved in each release sequence will be discussed with release fractions in Section 4.2.2.

Accident Occurs (X1)

The accident rate for truck transport in the U.S. is $1.55 \times 10^{-6}$ truck accidents per kilometer (Clarke 1976). The average shipping distance for uranium ore concentrates is 2660 kilometers (see Section 3). The expected accident frequency for uranium ore concentrate shipments, then, is $4.12 \times 10^{-3}$ accidents per shipment.

Container (Yellowcake Drum) Failed by Fire (X2)

Structural analysis of the yellowcake drums (see Appendix $C$ ), shows that yellowcake containers are not susceptible to failure by fire. This failure mechanism was therefore excluded from the remainder of the analysis.

Container (Yellowcake Drum) Failed by Puncture (X3)

The probability of a truck accident involving a puncture situation, given that an accident has occurred, is shown in Appendix $C$ to be 0.20 . For packages about the size of a yellowcake drum, about $6.8 \%$ of the drums are expected to be damaged in a puncture accident, on the average, if the puncture force is above a threshold failure point (Clarke 1976). From information presented in Appendix $C$, the probability of exceeding the puncture failure threshold for a yellowcake drum is about 0.025 . The probability value for failure of a yellowcake drum by puncture forces is $(0.20)(0.068)(0.025)$, or $3.4 \times 10^{-4}$. This value contains the probabilities of puncture for both retained and ejected containers. Container Failed by Immersion (X4)

The probability of experiencing immersion, given that an accident has occurred, is $7.0 \times 10^{-6}$ (Clarke 1976). From the structural analys is of yellowcake drums (presented in Appendix C), an immersion depth of over $7.8 \mathrm{~m}(25.8 \mathrm{ft}$ ) must be experienced to fail the drums. From Appendix $C$, the probability of 
experiencing a depth greater than $7.8 \mathrm{~m}$, given an immersion accident, is 0.007 . Thus, the total probability of a container being failed by immersion forces, given a truck accident has occurred, is $4.9 \times 10^{-8}$.

Impact Forces Produced in Accident (X5)

The impact environment for the yellowcake drums is assumed to be present in all collision and overturn accidents, which represent 89.4 percent of expected truck accidents (Clarke 1976). The value used for this event is 0.894 impacts per accident.

Drums Are Ejected From Van (X6)

In the transportation of uranium ore concentrates, a release of material presents risks to the public only if it is allowed to escape the trailer or van. It is thus important to determine the probability of the van being breached by the energy of the separate yellowcake containers that is created in an impact accident. According to information presented by Sandia Laboratories, the probability of a van being breached, given that a collision or overturn accident has occurred, is 0.06 (Clarke 1976, p. 48). This value is used for this event.

Drums Failed by Impact Forces (X7)

Information in Appendix $C$ suggests that the yellowcake drums can survive an impact that is equivalent to a drop onto an unyielding surface from a height of 1.2 meters. For a container of about $360 \mathrm{~kg}$, essentially all impacts experienced will be equivalent to a 0.5 meter drop or less (Clarke 1976). The likelihood of drum failure by impact is thus very small. Based on engineering judgement, a value of 0.01 is used for this event.

Crush Forces Produced in Accident (X8)

Information from Sandia Laboratories (Clarke 1976) suggests that crush forces are produced in all impact accidents. The value used for this event is thus the same as for event $\times 5$, or 0.894 .

Crush Forces Sufficient to Fail Drums (x9)

Crush forces are the result of inertial loadings on the container by other containers within the truck trailer. Results of structural analysis on the 
yellowcake drums, presented in Appendix $C$, show that a crush force of approximately $9525 \mathrm{~kg}$ or a deceleration of over $3 \mathrm{~g}$ is required to fail the drums. Sandia information, reproduced in Appendix $C$, indicates that this level of force or greater may be expected in about $15 \%$ of collision accidents. Therefore, a value of 0.15 is used for this event.

Drums Ejected from Van in Crush Accident (X10)

As explained in event $\times 6$, a release of material will present risks to the public only if it is allowed to escape the van. As in event $X 6$, the probability of van breach is 0.06 .

The basic event probabilities presented above and detailed in Appendix $C$ provide the basis for evaluating the probability of each release sequence identified in the fault tree. The probabilities of the release sequences for uranium ore concentrate shipments by truck are shown in Table 4.3 .

The low probability values associated with failure of the yellowcake drums by fire or immersion forces suggest that these sequences will have little effect on final risk values. These sequences are not analyzed for release fractions, since they do not contribute significantly to the system risk.

Table 4.3. $\begin{aligned} & \text { Release Sequences and Probabilities for Uranium } \\
& \text { Ore Concentrate Shipments by Truck (per shipment) }\end{aligned}$
\begin{tabular}{ll}
$\begin{array}{l}\text { Release Sequence } \\
\text { Probability }\end{array}$ & Release Sequence \\
\hline $\begin{array}{l}\text { Negligible } \\
1.4 \times 10^{-6}\end{array}$ & $\times 1 \times 2$ \\
$2.0 \times 10^{-10}$ & $\times 1 \times 4$ \\
$2.2 \times 10^{-6}$ & $\times 1 \times 5 \times 6 \times 7$ \\
$3.3 \times 10^{-5}$ & $\times 1 \times 8 \times 9 \times 10$
\end{tabular}

\subsubsection{Release Fractions}

The final step in the evaluation of release sequences is the estimation of release fractions. Yellowcake powder is assumed to reach the public primarily 
by the air pathway. To estimate the airborne release from a uranium ore concentrate transportation accident, we need to know the quantity of material that can potentially affect the public that is released and dispersed by the wind.

Only puncture, impact and crush release sequences are of a sufficiently high probability to consider calculation of release fractions. However, in failure of the drums by puncture, only a few drums (6.8\%, or 3 drums) are even affected. Furthermore, the amount of material released from a "small" hole is not likely to be very great, particularly when compared to the release of a larger quantity of yellowcake from 10 to 20 drums failed in an impact accident. Although the puncture accident sequence is about as likely to occur as the impact sequence, the consequences from puncture will be negligible compared to those from impact because of the small amount of material released. On the bas is that puncture accidents would contribute little to the overall risk, this release sequence is not analyzed further in this report.

The two release sequences of most interest are from impact and crush accidents. These accidents are relatively probable and are likely to have the greatest consequences in terms of amount of material released to the public. The release fractions for these sequences are presented below. The details of the methodology for the evaluation of airborne release fractions and the application of these techniques for this study are presented in Appendix D.

In the release sequence where the drums are failed by impact forces, the van is assumed to be breached in an impact accident and intact drums escape. The drums are assumed to fail as they hit the ground. Failure of drums inside the van has been found to be more realistically modeled by crush failure. The yellowcake is assumed to pour from the drums after the drums are on the ground. It is estimated that only a small part of the material will be dispersed. The resultant release quantities of respirable airborne material for a variety of windspeeds are shown in Table 4.4. The assumptions and calculations leading to these release fractions are detailed in Appendix $D$.

In the release sequence where the drums are failed by crush forces, failed drums escape the van. The number of failed drums involved in this sequence is determined from information presented in Appendix C (about $80 \%$ of the drums will fail in the postulated crush accident and escape from the truck trailer). 
TABLE 4.4. Estimated Release Quantities for Impact and Crush Accidents (from Appendix D)

\begin{tabular}{|c|c|c|c|c|}
\hline \multirow{2}{*}{$\begin{array}{l}\text { Wind Speed } \\
(\mathrm{m} / \mathrm{sec})\end{array}$} & \multicolumn{2}{|c|}{$\begin{array}{l}\text { Respirable } \\
\text { Airborne }(\mathrm{kg})\end{array}$} & \multicolumn{2}{|c|}{$\begin{array}{l}\text { 24-Hour Resuspension } \\
\text { Sandy Soil }(\mathrm{kg})(\mathrm{a})\end{array}$} \\
\hline & Impact & Crush & Impact & Crush \\
\hline 1 & 0.5 & 3.9 & 1.1 & $3.09 \times 10^{-5}$ \\
\hline 3.5 & 2.3 & 19.3 & 3.7 & $3.09 \times 10^{-5}$ \\
\hline 7 & 4.2 & 34.7 & 18.0 & $3.09 \times 10^{-5}$ \\
\hline 10 & 6.0 & 50.2 & 69.4 & $3.09 \times 10^{-5}$ \\
\hline 18 & 11.3 & 94.5 & 462.7 & $3.09 \times 10^{-5}$ \\
\hline
\end{tabular}

(a) Although the number of significant figures exceeds the accuracy of the data, the numbers are kept to minimize inaccuracies in their further use.

It is assumed that the airborne drums tumble through the air, and loose powder subsequently falls to the ground. The powder intermixes with air, more than in the impact release sequence. Again, the calculations involved in an estimation of the releases for the crush accident sequence are detailed in Appendix $D$. The results of these calculations for releases of respirable airborne material for a variety of windspeeds are shown in Table 4.4.

This section of the report has developed the potential release sequences of importance for the shipment of yellowcake by truck. Fault tree methodology was used to delineate possible release sequences. An analys is of the probabilities of each basic event in the sequence provided information on the expected frequency of occurrence of each postulated release sequence. Information on release quantities was then obtained to gain some understanding of the relative consequences of the release.

At this point, a risk number could be obtained by multiplying the individual release sequence probabilities and release fractions together and summing over all release sequences. The resulting risk number, however, would be relatively meaningless in terms of identifying potential effects to the public as a result of a yellowcake release. To express the risk in a more useful form (in this case, fatalities), conversion factors must be developed to reflect the 
real consequences of a yellowcake release. These factors, which account for the health effects of yellowcake, are given in the following section of the report. 


\subsection{EVALUATION OF ENVIRONMENTAL CONSEQUENCES}

The purpose of this section is to develop conversion factors that will allow the calculation of risk in terms of potential fatalities as a result of a yellowcake release. Parameters which must be evaluated include: health effects of a material release, meteorology, demography, and quantity of the release made airborne and dispersed.

\subsection{HEALTH EFFECTS}

Uranium ore concentrates present both a chemical and a radiological health hazard when inhaled. The chemical effects of yellowcake are due to the toxicity of the heavy metal, uranium. The radiological effects stem from exposure to the radioactive isotopes of natural uranium.

The extent of the health effects experienced with an inhalation of yellowcake is dependent on the solubility of the material. As an insoluble compound, uranium deposited in the lungs is slow to be eliminated from the body; its major effect is associated with the radiological hazard caused by continued exposure. As a soluble compound, the chemical toxicity of uranium is more evident and can result in damage to the exchange organs, especially the kidneys.

The identification of the solubility of yellowcake is difficult because the substance may be composed of a variety of materials. The actual composition of yellowcake may include a number of uranium compounds. Ammonium diuranate, which is soluble, is generally produced from milling operations. However, during the drying process, the chemical structure of the yellowcake product may change to uranium octoxide, which is an insoluble compound, as a result of thermallyinduced decomposition. Solubility studies done on yellowcake products show an average solubility classification for the material of $60 \%$ soluble, $40 \%$ relatively insoluble (Kalkwarf 1979). These values are used for the purposes of determining health effects in this report.

For the purposes of this study, both radiological and chemical health effects of uranium were investigated. In determining the health effects of yellowcake, it was assumed that the uranium compounds in the material were 
composed of three isotopes, ${ }^{234} \mathrm{U},{ }^{235} \mathrm{U}$, and ${ }^{238} \mathrm{U}$, in proportions found in natural uranium. The fractional curie composition by isotope is shown in Table 5.1.

TABLE 5.1. Isotopic Composition of Yellowcake

$\begin{array}{ll}\frac{\text { Isotope }}{234_{U}} & \frac{\text { Ci/kg-Yellowcake }}{3.06 \times 10^{-4}} \\ 235_{U} & 1.52 \times 10^{-5} \\ 238_{U} & 3.26 \times 10^{-4}\end{array}$

In estimating the hazard from airborne releases, the inhalation potential of the source material is important. The size of the particles in the release provide an index to the hazard. Particles of less than 10 microns in diameter, if inhaled, will be adsorbed in the bronchial system. Particles of a larger size, when inhaled, are immediately expelled from the body or trapped in the nose or throat passageways. For the purposes of this analys is, an average of $25 \%$ of the yellowcake release is of a respirable size, or less than 10 microns in diameter. The derivation of this value is discussed in Appendix B.

The primary health effect of the inhalation of insoluble uranium compounds is radiological. Dose conversion factors used to predict the heal th effects were calculated by the computer program DACRIN (Houston et. al. 1974) for the uranium isotopes of interest and are shown in Table 5.2. These factors relate the effective radiation dose in rem from breathing air contaminated to $1 \mathrm{Ci} / \mathrm{m}^{3}$ with respirable size particles for one second. Appropriate scaling is linear for atmospheric concentrations and exposure periods. The health effects that could be associated with a radioactive material release can be divided into three categories. These are early fatalities (fatalities that occur within one year), early $i 11$ nesses (people needing medical treatment) and late health effects that are estimated from the total population dose. In general, early effects are associated with individual total body doses of 100 rads or more and would be limited to persons in the immediate vicinity of rather large releases of radioactivity, such as the severe reactor accidents covered in WASH-1400. The 
TABLE 5.2. Dose to Critical Organ Via Inhalation of Uranium Compounds (a)

$$
\frac{\mathrm{Rem}-\mathrm{m}^{3}}{\mathrm{C} i-\mathrm{sec}}
$$

\begin{tabular}{|c|c|c|c|c|}
\hline \multirow[b]{2}{*}{ Radionuclide } & \multirow{2}{*}{$\begin{array}{l}\text { Dose Time } \\
\text { (Years) }\end{array}$} & \multicolumn{3}{|c|}{ Dose Conversion Factor } \\
\hline & & Lung & Bone & Total \\
\hline insoluble) & 50 & $1.562 E+5$ & $1.536 E+3$ & 9.50 \\
\hline${ }^{235} \mathrm{U}$ (insoluble) & 50 & $1.467 \mathrm{E}+5$ & $1.472 \mathrm{E}+3$ & $8.920 E+1$ \\
\hline${ }^{238}$ U (insoluble) & 50 & $1.371 E+5$ & $1.408 \mathrm{E}+3$ & $8.338 E+1$ \\
\hline
\end{tabular}

(a) Task group on Lung Dynamics Mode $1-7.5 \mathrm{hr}$ inhalation duration, $350 \mathrm{cc} / \mathrm{sec}$ breathing rate.

(b) Read $1.562 \times 10^{5}$.

transportation of yellowcake, however, involves small amounts of radioactivity and the public is assumed to be excluded from the immediate area of an accident. Thus, potential doses to individuals in a transportation accident would be below levels that could produce early health effects.

Late health effects, including latent cancer fatalities, are assumed to result from the exposure of populations to low levels of radioactivity. Predicted magnitudes of these effects are based on observed health effects produced at high dose levels and a hypothesis of linearity between effect and dose. Detailed discussions of health effects and health effects models can be found in NCRP 1975, EPA 1974, and BEIR 1972(a). Conversion of population doses in man-rem to estimated possible cancer deaths was based on the factors presented in Table 5.3. These conversion factors enable a comparison of radioactive material transportation risk estimates with other societal risks.

As a soluble compound, the chemical toxicity of uranium becomes important in the calculation of health effects. The chemical toxicity is the result of a gradual buildup of uranium in the tissue of the kidney after uranium compounds have been absorbed in the blood. Though much has been written concerning the

(a) The latest BEIR report (1980) says the risk of cancer death from low radiation exposure is only half of what it was thought to be eight years ago. Use of these latest results would reduce the risk determined in this analysis accordingly. 
TABLE 5.3. Health Effects Conversion Factors-Population Dose to Maximum Number of Health Effects

\begin{tabular}{|c|c|c|}
\hline \multirow[b]{2}{*}{ Organ of Reference } & \multicolumn{2}{|c|}{$\begin{array}{l}\text { Predicted Incidence of Fatal Cancers } \\
\quad \text { Per } 10^{6} \mathrm{man}-\mathrm{rem}(\mathrm{a})\end{array}$} \\
\hline & Range of Values & Value Used(b) \\
\hline \multicolumn{3}{|l|}{ From: } \\
\hline Lung Exposure & $16-110$ & 50 \\
\hline Bone Exposure & $2-17$ & 6 \\
\hline Total Body Exposure & $50-450$ & 200 \\
\hline
\end{tabular}

(a) Derived from the 1972 BEIR Report.

(b) From EPA-520/4-73-002 based on BEIR statistics.

chemical toxicity of uranium, precise quantification is difficult. The maximum permissible concentration (MPC) of uranium is $0.210 \mathrm{mg} / \mathrm{m}^{3}$ air. The International Commission of Radiological Protection (ICRP) gives a value of $2.5 \mathrm{mg}$ inhaled as acceptable (1962). Ten $\mathrm{mg}$ inhaled is suggested as a maximum emergency planned occupational dose (Eve 1964). Little information is available on fatal inhalation or ingestion levels. A level of $100 \mathrm{mg}$ uranium dissolved in the blood is assumed to result in eventual death, based on available information on the effects of yellowcake in the body and on expert opinion. Table 5.4 gives the uranium levels and effects assumed for this study.

The release fractions obtained in Section 4.2.2 must be modified to allow a conversion of release fraction to potential fatalities. The calculated release fractions are presented in Table 4.4 in terms of the amount of respirable

TABLE 5.4. Assumed Limits and Chemical Health Effects of the Inhalation of Uranium

$\begin{array}{cl}<2.5 \mathrm{mg} \text { inhaled } & \text { No Effect } \\ 10.0 \mathrm{mg} \text { inhaled } & \text { Minimal Health Effect } \\ 100.0 \mathrm{mg} \text { dissolved } & \text { Assumed Fatal } \\ \text { in the blood } & \end{array}$


yellowcake (in $\mathrm{kg}$ ) released in a transportation accident. To relate these release fractions to the assumed level of uranium intake required for eventual death, a conversion factor must be developed.

First, the uranium content of yellowcake must be accounted for. This value $(0.674 \mathrm{~kg} \mathrm{U} / \mathrm{kg}$ yellowcake) is derived by using the relationship between the molecular weights of uranium and $\mathrm{U}_{3} \mathrm{O}_{8}$ and the fact that yellowcake is assumed to be composed of $80 \% \mathrm{U}_{3} \mathrm{O}_{8}$. Of this amount, $60 \%$ is assumed to be composed of soluble uranium compounds. The release fractions obtained in Section 4.2.2 must thus be modified by a factor of $(0.674)(0.60)$ or 0.407 to obtain the amount of soluble, natural uranium released in the respirable size range.

Secondly, the physical process of inhalation must be considered. When an aerosol is inhaled, a filtering process occurs in the nose and throat areas. Thus, not all of the material that is inhaled will actually be retained in the lung and absorbed in the blood. Retention fractions for various organs were obtained from the ICRP Task Group on Lung Dynamics, 1966. This information suggests that only $46 \%$ of the material inhaled will be retained in the body and absorbed in the blood.

Combining the necessary health effects conversion factors, as shown below in Equation (5-1) yields a factor for potential chemically-caused fatalities of $1.87 \times 10^{-3}$ fatalities per mg of yellowcake inhaled. The amount of yellowcake actually inhaled will depend on the dispersion of the material, discussed in Section 5.4 of this report, and the breathing rates of individuals. As in radiological lung models, a breathing rate of $350 \mathrm{~cm}^{3} / \mathrm{sec}$ over 7.5 hours is assumed.

$$
\left(\frac{1 \text { fatality }}{100 \mathrm{mg} U \text { inhaled }}\right) \times(0.407) \times(0.46)=1.87 \times 10^{-3} \frac{\text { fatalities }}{\mathrm{mg}}
$$

\subsection{METEOROLOGY}

The diffusion climatology along the transport route must be incorporated into any risk analysis where the atmosphere is an important pathway for dosage to man. The important atmospheric variables are wind speed, which indicates the rate of transport, and atmospheric stability, which indicates the rate of dilution and plume rise potential. 
Assuming a postulated accident with a surface release and little or no release-related plume rise, the immediate and greatest impact will be in the region surrounding the location of the event. Transport and diffusion are often affected by local influences, such as topography and proximity to large bodies of water. Wind speeds and directions show considerable variation that cannot always be generalized for large geographic regions. The inclusion of such influences in the present analysis is not feasible, principally because the information is not available either from a data base or from current modeling capabilities. However, the variety of meteorological states examined should provide sufficient analysis of the possible states that could be experienced locally. The lack of localized data will not significantly affect the validity of the overall analysis.

The meteorological data used in this analysis are shown in Table 5.5. The values were developed from micrometeorological data collected for diffusion calculations for reactor sites. Seven sets of micrometeorological data were selected from about 26 compilations from reactor sites to account for the range of conditions that could reasonably occur along the route. The use of a single averaged distribution allows for the typical range of wind speeds without undue weighting to any particular site. Although this result cannot be expected to necessarily represent any particular portion of the route, it does represent the type of conditions that may be encountered on the average.

TABLE 5.5. Average Wind Speed/Stability Characteristics

\begin{tabular}{|c|c|c|c|c|c|c|}
\hline \multicolumn{3}{|c|}{$\frac{\text { Wind Speed }}{U_{1}(a)}$} & \multicolumn{4}{|c|}{$\frac{\text { Pasquill Stability Classification }}{P_{i}(b) / k(a)}$} \\
\hline $\begin{array}{l}U_{k}(a) \\
m / \sec \end{array}$ & k & $P_{k}$ & $B(j=1)$ & $\begin{array}{r}P_{j}(b \\
D(j=2)\end{array}$ & $\begin{array}{l}\text { (a) } \\
E(j=3)\end{array}$ & $F(j=4)$ \\
\hline 1 & 1 & 0.255 & 0.136 & 0.202 & 0.299 & 0.363 \\
\hline 3.5 & 2 & 0.508 & 0.243 & 0.274 & 0.272 & 0.211 \\
\hline 7 & 3 & 0.161 & 0.190 & 0.290 & 0.339 & 0.181 \\
\hline 10 & 4 & 0.052 & 0.240 & 0.312 & 0.358 & 0.090 \\
\hline 18 & 5 & 0.024 & 0.276 & 0.348 & 0.356 & 0.020 \\
\hline
\end{tabular}

(a) $k$ is the wind speed index.

(b) $j$ is the atmopheric stability classification index. 


\subsection{DEMOGRAPHY}

To determine the number of people affected by a yellowcake release resulting from a transportation accident, the population distribution along the shipping route must be characterized. This was accomplished by dividing the continental U.S. into four zones based roughly on population density and degree of urbanization. Population densities were grouped into three classes: urban, for densely populated urban areas; suburban, for areas of moderate population density; and rural, for the nonurbanized areas.

To establish population data for the representative zones, Bureau of the Census information for 1960 was used as a base. This information was extended to 1970 with data from the 1970 census. Population projections were made to 1980,1990 , and 2000, using the compound interest formula to model population growth. Projected population densities and land areas used in this study are presented in Table 5.6.

TABLE 5.6. Projected Population Density and Land Area by Zone and Population Classes

\begin{tabular}{|c|c|c|c|c|c|c|}
\hline \multirow{2}{*}{$\begin{array}{c}\text { Zone and } \\
\text { Population } \\
\text { Classes }\end{array}$} & \multicolumn{2}{|c|}{1980} & \multicolumn{2}{|c|}{1990} & \multicolumn{2}{|c|}{2000} \\
\hline & $\begin{array}{l}\text { Land } \\
\text { Area, \% }\end{array}$ & $\begin{array}{l}\text { Density } \\
\text { People/m } \\
\end{array}$ & $\begin{array}{l}\text { Land } \\
\text { Area, \% }\end{array}$ & $\begin{array}{l}\text { Density } \\
\text { People/m }\end{array}$ & $\begin{array}{l}\text { Land } \\
\text { Area, \% }\end{array}$ & $\begin{array}{r}\text { Density } \\
\text { People/m } \\
\end{array}$ \\
\hline I Urban & 3.8 & $3.587 \mathrm{E}-3$ & 4.8 & $3.239 \mathrm{E}-3$ & 6.0 & $2.923 E-3$ \\
\hline Suburban & 66.9 & $3.174 E-4$ & 84.3 & $3.448 E-4$ & 94.0 & $3.880 \mathrm{E}-4$ \\
\hline Rural & 29.3 & $2.363 E-4$ & 10.9 & $2.687 E-4$ & -- & -- \\
\hline I I Urban & 11.5 & $1.224 E-3$ & 14.5 & 1.208E-3 & 18.2 & $1.089 E-3$ \\
\hline Suburban ${ }^{(a)}$ & 35.5 & $3.263 E-4$ & 44.8 & $2.942 E-4$ & 56.5 & $2.649 E-4$ \\
\hline Rural & 53.0 & $9.189 E-5$ & 40.7 & 1. $351 E-4$ & 25.3 & $2.452 E-4$ \\
\hline I I Urban & 0.8 & $1.537 E-3$ & 1.0 & $1.517 E-4$ & 1.2 & $1.502 E-3$ \\
\hline Suburban $(a)$ & 17.3 & $8.726 E-3$ & 21.8 & $8.610 E-5$ & 27.5 & $8.533 E-5$ \\
\hline Rural & 81.9 & $6.564 E-6$ & 77.2 & $9.266 \mathrm{E}-6$ & 71.3 & $1.120 \mathrm{E}-5$ \\
\hline IV Urban & 0.5 & $1.695 \mathrm{E}-3$ & 0.6 & $1.730 E-3$ & 0.8 & $1.761 E-3$ \\
\hline Suburban $(a)$ & 15.0 & $5.058 \mathrm{E}-5$ & 18.9 & $5.560 \mathrm{E}-5$ & 23.7 & $5.676 E-5$ \\
\hline Rural & 84.5 & $9.653 E-6$ & 80.6 & $1.120 E-5$ & 75.5 & $1.313 E-5$ \\
\hline
\end{tabular}

(a) SMSA minus cities. 
A second factor in the characterization of the demography is to relate the shipment route to the population zones. Yellowcake shipment routes were previously determined in Section 3.

A map of the population zones and the locations of the facilities shipping and receiving yellowcake are shown in Figure 5.1. The designations $P-1, P-2$, $M-1, M-2$, etc. refer to the $U_{6}$ production plants and the uranium ore mills listed in Table 5.7. (a) Distances between shipping and receiving facilities were obtained from Rand McNally maps (1973). For each shipping route, the fraction of the route in each population zone was determined from the maps. This data is summarized in Table 5.8. A listing of the fractional mileage for each individual route is presented in Table 5.9. The shipping and receiving facilities used in this table are those listed in Table 5.7.

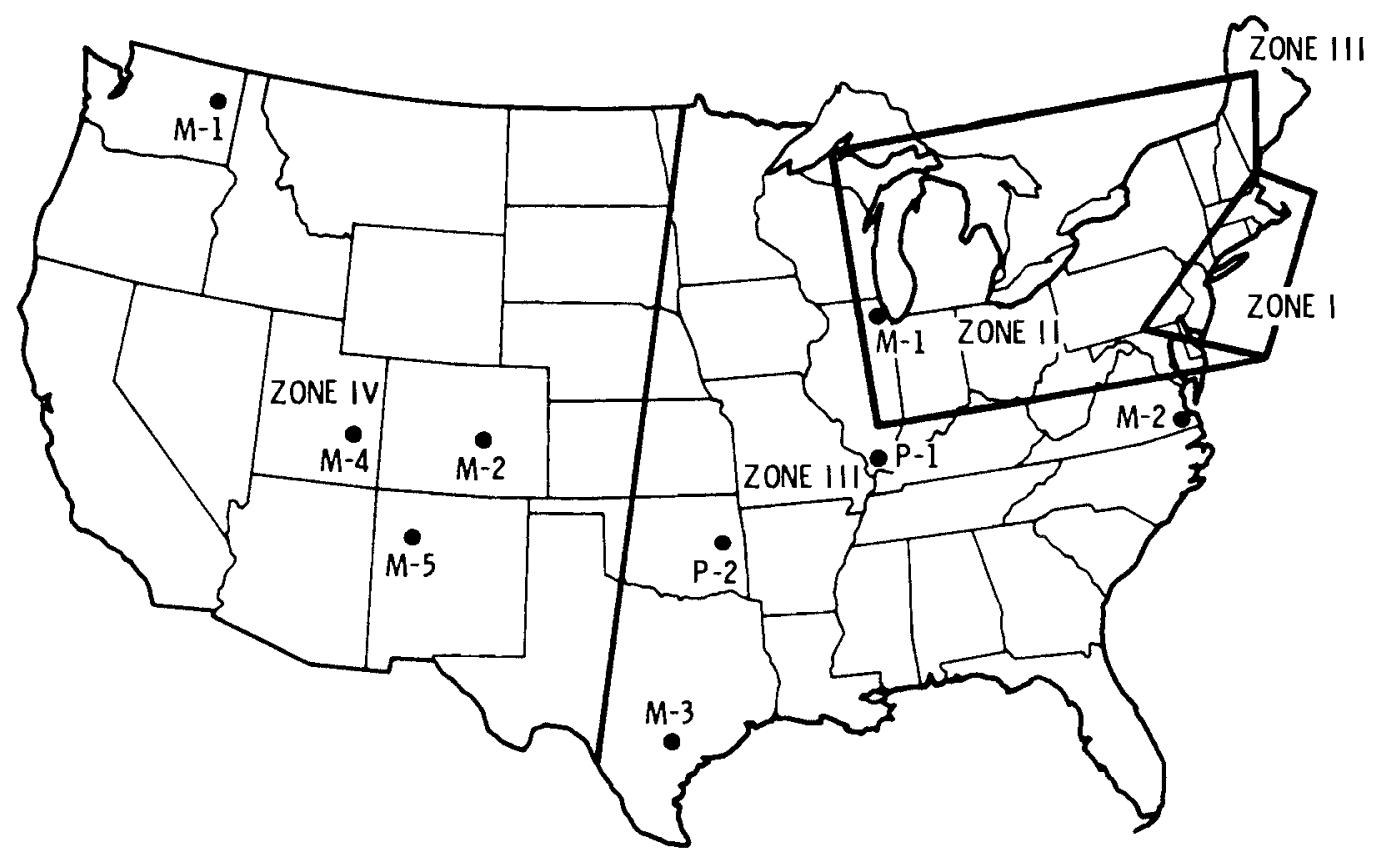

FIGURE 5.1. Population Zones and Yellowcake Shipping and Receiving Facilities (See Table 5.7)

(a) All material imported from foreign sources was assumed to enter the country through Baltimore, Chicago, or Norfolk. 
TABLE 5.7. Yellowcake Shipment Origins and Destinations

\begin{tabular}{|c|c|c|}
\hline $\begin{array}{c}\text { Domestic Shipment } \\
\text { Origins } \\
\end{array}$ & $\begin{array}{c}\text { Import Shipment } \\
\text { Origins }\end{array}$ & $\begin{array}{c}\text { Shipment } \\
\text { Destinations } \\
\end{array}$ \\
\hline M-1 Canon City, Co & M-7 Baltimore, MD & P-1 Metropolis, IL \\
\hline M-2 Casper, WY & M-8 Chicago, IL & P-2 Sequoyah, OK \\
\hline M-3 Falls City, TX & M-9 Norfolk, VA & \\
\hline M-4 Ford, WA & & \\
\hline M-5 Grants, NM & & \\
\hline M-6 Moab, UT & & \\
\hline
\end{tabular}

TABLE 5.8. Fractional Mileage of Shipping Routes by Population Zone

$\begin{array}{cllllll}\text { Zone } & \text { I } & \text { II } & \text { III } & \text { IV } \\ \begin{array}{l}\% \text { of Total Shipment } \\ \text { Miles in Zone }\end{array} & 0 & 2.5 & 50.7 & 46.8\end{array}$

TABLE 5.9. Fractional Mileage of Shipping Routes by Population Zones (Values in Percent)

\begin{tabular}{ccccccc}
\multicolumn{3}{l}{ Facilities } & \multicolumn{3}{c}{ Population Zones } \\
\cline { 5 - 6 } From & To & & I & II & III & IV \\
M-1 & P-1 & -- & -- & 56 & 44 \\
M-2 & P-1 & -- & -- & 47 & 53 \\
M-2 & P-2 & -- & -- & 39 & 61 \\
M-3 & P-1 & -- & -- & 100 & -- \\
M-3 & P-2 & -- & -- & 100 & -- \\
M-4 & P-2 & -- & -- & 23 & 77 \\
M-5 & P-1 & -- & -- & 58 & 42 \\
M-5 & P-2 & -- & -- & 30 & 70 \\
M-6 & P-1 & -- & -- & 46 & 54 \\
M-7 & P-1 & -- & 22 & 78 & -- \\
M-8 & P-1 & -- & 67 & 33 & -- \\
M-8 & P-2 & -- & 28 & 72 & -- \\
M-9 & P-1 & -- & -- & 100 & --
\end{tabular}




\subsection{ATMOSPHERIC DISPERSION MODEL}

A yellowcake release must reach man via some pathway in his environment to present any danger to human life. For the purpose of this study, only the air pathway was considered. The atmospheric dispersion of the released yellowcake can be evaluated by the bivariate Gaussian distribution equation (Turner 1970), given by:

$$
E(x, y, z ; H)=\frac{Q t}{2 \sigma_{y} \sigma^{U}} \exp \left[-1 / 2\left(\frac{y}{\sigma_{y}}\right)^{2}\right]\left\{\exp \left[-1 / 2\left(\frac{z-H}{\sigma_{z}}\right)^{2}\right]+\exp \left[-1 / 2\left(\frac{z+H}{\sigma_{z}}\right)^{2}\right]\right\}
$$

where

$$
\begin{aligned}
E= & \text { time integrated concentration at }(x, y, z) ;\left(\mathrm{g} / \mathrm{m}^{3}\right) \\
H= & \text { release height; }(\mathrm{m}) \\
\sigma_{\mathrm{y}}, \sigma_{z}= & \text { Pasquill dispersion parameters representing standard deviation of } \\
& \text { crosswind and vertical plume concentration distribution; (m) } \\
(\mathrm{x}, \mathrm{y}, \mathrm{z})= & \text { Cartesian coordinates of the point at which the concentration is } \\
& \text { being determined (release occurs at the origin);(m) } \\
t= & \text { time }(\mathrm{sec}) \\
Q= & \text { source emission rate; }(\mathrm{g} / \mathrm{sec}) \\
U= & \text { wind speed; (m/sec) }
\end{aligned}
$$

The concentration of yellowcake at a point $(x, y, z)$ can be obtained from Equation (5-2) by specifying wind speed, release height, and Pasquill dispersion parameters, which are dependent on the atmospheric stability at the time of release. Pasquill stability classifications were outlined in Table 5.5. Further detail on the atmospheric dispersion model used in these studies may be found in the TRECII manual (Franklin 1980).

The amount of the release received by the entire population could, in theory, be calculated by locating every individual or group of individuals along a shipping route and determining the concentration of yellowcake to which each was exposed. For this study, however, it was much simpler to determine 
the number of people affected by a certain level, namely that limit of concentration causing fatality. This was done by calculating lines of constant concentration, or isopleths, using Equation (5-2). Then, by integration, the area enclosed by such an isopleth was determined. A key assumption was that all individuals located for a specified time period within the isopleth representing a fatal concentration would be killed. This assumption results in a conservative estimate of risk. However, because of the characteristics of the population distribution along the transportation route, and the required time interval for potentially fatal health effects to occur, there were found to be no potential fatalities as a result of inhaling yellowcake released in a transportation accident. 



\subsection{THE RISK OF SHIPPING URANIUM ORE CONCENTRATES BY TRUCK}

The concept of risk includes a consideration of the probability of a release of yellowcake to the environment as well as the consequences, in terms of potential public fatalities, resulting from that release. Risk is expressed by the following equation:

$$
R_{i}=\left(Q_{R_{i}} \times P_{R_{i}}\right) \times \sum_{q}\left(C_{E_{i, q}} \times P_{E_{q}}\right)
$$

The terms inside the first set of parentheses represent the product of the amount of material released in the $i$ th release sequence $\left(Q_{R_{j}}\right)$ times the expected frequency of occurrence of the release sequence $\left(P_{R_{j}}\right)$. The information needed to evaluate these terms was developed in Section 4 of this report. The two terms in the second set of parentheses represent the consequences of a material release $\left(C_{E_{j}, q}\right)$ and the expected frequency of encountering a given set of environmental and demographic conditions $\left(P_{E_{q}}\right)$. The primary purpose of Section 5 was to determine the factors required to evaluate the consequences of a release. The information required to determine the expected frequency of encountering a given environmental consequence was also presented; the development of the frequency of occurrence term is shown below.

This analysis treats the wind speed, weather stability class and population class as distributed variables. The expected frequency of encountering a given set of environmental conditions can be expressed as:

$$
P_{E_{q}}=P_{E_{j, k, l, m}}=P_{j / k} P_{k} P_{\ell / m} P_{m}
$$

where

$j$ is the atmospheric stability classification index

$k$ is the wind speed index

$\ell$ is the population density index in zone $m$ of the U.S.

$m$ is the zone index for the shipping routes 
The notation $j / k$ indicates that the expected frequency of encountering the $j$ th stability class is a function of the wind speed existing at the time of release. Similarly, the expected frequency of encountering the $e^{\text {th }}$ population density is dependent on the expected frequency that a shipment will pass through zone $\mathrm{m}$. By specifying a value for $j, k, l$, and $m$, one can obtain the expected frequency that an environmental condition will be experienced during a shipment. Associated with that frequency is a corresponding value for the environmental consequences. The product $\left(C_{E_{j, q}} \times P_{E_{q}}\right)$ has units of population health effects, in terms of fatalities, per gram of material released.

In this section, the risk of shipping uranium ore concentrates by truck will be discussed. The risk was calculated using the methodology discussed above and in Appendix A. The probability of an accidental release occurring during transport was determined in Section 4, and the consequences of each release type were discussed in Section 5. Section 6.1 discusses the risk of shipping yellowcake in the mid-to-late 1980s based on the shipping system model given in Section 3.

\subsection{RISK EVALUATION OF URANIUM ORE CONCENTRATE SHIPMENTS}

The risk involved with shipping uranium ore concentrates by truck was determined by summing the risks associated with each release sequence. A summary of the model shipping system upon which these calculations were based is shown in Table 6.1. Based on this information, accidents involving truck shipments of yellowcake would be expected to occur at a rate of about ten a year. However, only one-fifth of these accidents, or less than two a year, are expected to result in a release of yellowcake to the environment. These results are based on the release sequence probabilities determined in Section 4 . None of these accidents were expected to release sufficient material to cause a potential

TABLE 6.1. Simplified Uranium Ore Concentrates Shipping System Model

\begin{tabular}{|c|c|c|c|c|c|c|c|}
\hline $\begin{array}{l}\text { Shipping } \\
\text { Container }\end{array}$ & $\begin{array}{l}\text { Transport } \\
\text { Mode }\end{array}$ & $\begin{array}{c}\text { Amount/ } \\
\text { Container (MT) }\end{array}$ & $\begin{array}{l}\text { Conta iners/ } \\
\text { Shipment }\end{array}$ & $\begin{array}{l}\text { Material } \\
\text { Shipped/ } \\
\text { Year (MT) }\end{array}$ & $\begin{array}{c}\text { Number of } \\
\text { Shipments / } \\
\text { Year }\end{array}$ & $\begin{array}{c}\text { Average } \\
\text { Shipment } \\
\text { Distance }(\mathrm{km})\end{array}$ & $\begin{array}{c}\text { Accident/ } \\
\mathrm{km}\end{array}$ \\
\hline 55-gal drum & truck & 0.36 & 50 & 45,700 & 2544 & 2660 & $1.55 \times 10^{-6}$ \\
\hline
\end{tabular}


fatality. The estimated radiological dose to the general public as a result of a yellowcake release was determined to be insignificant (no fatalities were calculated); that is, no difference in background levels currently experienced could be discerned as a result of yellowcake transportation accident releases.

The minimum concentration of yellowcake in air necessary to cause a fatality (over a 24-hour exposure period) was found to be $0.057 \mathrm{~g} / \mathrm{m}^{3}$. Any exposure less than 24 hours was insufficient to cause a fatality. The largest area that an isopleth of this concentration was found to cover was about $260 \mathrm{~m}^{2}$. Using the population densities discussed in Section 5.3, even travel through an urban zone was not expected to cause fatalities.

In an attempt to estimate the limits of a yellowcake accident that could potentialiy cause a fatality, the parameters of the risk equation (Equation 6-1) were varied. The first case was to vary $Q_{R_{j}}$, or the amount of material released in an accident. In this analysis, a worst case release was assumed where all drums ejected from the van 1ost $100 \%$ of their contents upon failure. This material was then made available for dispersion. Again, the minimum concentration (continuous over a 24-hour exposure period) required to cause a potential fatality was $0.057 \mathrm{~g} / \mathrm{m}^{3}$. The isopleth of fatal concentration now had a maximum area of about $330 \mathrm{~m}^{2}$. Using the population densities in section 5.3, a maximum of one potential fatality could be experienced only in the urban regions of Zone 1 . However, yellowcake shipments do not travel through this zone at all, so it would be very unlikely for a fatality to be experienced. Furthermore, it is improbable that a person would be exposed continuously for 24 hours. Thus, even a larger and highly improbable release does not affect the risk results.

A second case involved adjustments to the parameter $P_{R_{j}}$, or the expected frequency of occurrence of a release. Increases to this factor simply increase the number of accidents or releases per year that might be expected to occur from transportation of yellowcake. This value does not affect the health effects of an accidental release. Thus, if no fatalities are experienced with the base case assumptions, adjustments to this parameter cannot produce expected fatalities unless the same people are continuously exposed to all accidents.

A third parameter varied was the consequence of an expected release $\left(C_{E_{i, q}}\right)$ in terms of the level of uranium intake required to cause a fatality. A uranium 
intake of 60 percent of the base case was assumed necessary to cause a fatality (60 mg uranium inhaled and absorbed in the blood). This is a level of intake which has proven to be toxic to the kidney, although not necessarily fatal. Below this level, effects are usually nonfatal. Adjustments to this parameter had no significant effect on final risk values. The general size of the isopleth of fatal concentration levels changed by less than $4 \%$ (from $260 \mathrm{~m}^{2}$ to about $270 \mathrm{~m}^{2}$ ).

Last, the parameter of the probability of encountering various environmental conditions was varied. Even using worst case environmental conditions, a person would still need to be exposed to the release for a continuous time period of 24 hours. While it is highly improbable that these environmental conditions would hold for this time period, it is even more unlikely that a person would remain, unsheltered, in the contaminated area of $260 \mathrm{~m}^{2}$ for a period of at least 24 hours.

The results of this study indicate that the risk to the public of shipping yellowcake is extremely low. This is primarily due to the low concentration of radioactivity distributed throughout yellowcake and the physical and chemical characteristics of the material. Even in instances where large releases of the material have occurred, no injury to personnel was evident. In 1977, for example, a truck carrying 18 MT of yellowcake overturned, releasing about $3175 \mathrm{~kg}$ of the material to the environment. Yet the people involved in the rescue and cleanup operation had only minor ingestion of uranium, based on bioassay results, although they had been exposed to large concentrations of the powder for several hours (Smith 1978). The concentrations measured were a factor of more than 100 below the levels where any physical effect could be observed.

Further perspective on the total risk to the public from transporting yellowcake may be gained by examining the benefits provided by this energy material. The energy content of uranium is quite high making the amount of material transported relatively small in view of the amount of energy that can be produced from it. For example, 180 MT of yellowcake, or about 10 shipments, can supply a year's worth of fuel (after conversion) for a typical 1000 megawatt nuclear power plant. Nuclear power currently provides about $10 \%$ of the electricity generated in the U.S. (Jimison 1977). 


\section{REFERENCES}

Andrews, W. B. 1980. An Assessment of the Risk of Transporting Liquid Chlorine by Rai1. PNL-3376, Pacific Northwest Laboratory, Richland, Washington.

Beir. 1972. The Effects on Population of Exposure to Low Levels of Ionizing Radiation. Report of the Advisory Committee on the Biological Effects of Ionizing Radiations, National Academy of Science.

Clarke, R. K. et al. 1976. Severities of Transportation Accidents. SLA-740001 , Sandia Laboratories, ATbuquerque, New Mexico.

Coleman, R. B. 1978. "Today's Uranium Mi11ing Costs." Mining Engineer. Vo1. 30, No. 10.

Dennis, A. W. et a1. 1978. Severities of Transportation Accidents Involving Large Packages. SAND77-0001, Sandia Laboratories, ATbuquerque, New Mexico.

Elder, H. K. et a1. 1978. An Assessment of the Risk of Transporting Spent Nuclear Fuel by Truck. PNL-2588, Pacific Northwest Laboratory, Richland, Washington.

EPA, Environmental Radiation Dose Commitment: An Application to the Nuclear Power Industry. 1974. EPA-520/4-73-002, U.S. EnvironmentaT Protection Agency, Washington, D.C.

Eve, I. S. 1964. "Some Suggested Maximum Permissible Single Intakes of Uranium." Health Physics. 10:773-776.

Frankiin, A. L. 1978. TRECII: A Computer Program for Transportation Risk Assessment. PNL-3208, Pacific Northwest Laboratory, Rich1and, Washington.

Geffen, C. A. et a1. 1980. An Assessment of the Risk of Shipping Propane by Truck and Train. PNL-3308, Pacific Northwest Laboratory, Richiand, Washington.

Geffen, C. A., J. F. Johnson et a1. 1978. An Assessment of the Risk of Transporting Uranium Hexafluoride by Truck and Train. PNL-2211, Pacific Northwest Laboratory, Richland, Washington.

Ha11, R. J. et a1. 1977. An Assessment of the Risk of Transporting Plutonium Dioxide and Liquid PTutonium Nitrate by Train. BNWL-1996, Pacific Northwest Laboratory, Richland, Washington.

Houston, J. R., D. L. Strenge, and E. C. Watson. 1974. DACRIN - A Computer Program for Calculating Organ Dose from Acute or Chronic Radionuclide Inhalation. BNWL-B-389, Pacific Northwest Laboratory, Richland, Washington (Reissued 1976). 
International Commission on Radiological Protection (ICRP). 1962. Recommendations of the International Commission of Radiological Protection. ICRP Publication 6, Pergamon Press, New York, New York.

ICRP Task Group on Lung Dynamics 1966. "Deposition and Retention Models for Internal Dosimetry of the Human Respiratory Tract," Health Physics. 12, 173.

Jimison, W. 1977. National Energy Transportation. Volume 1 - Current Systems and Movements, Congressional Research Service Publication, No. 95-15, Washington, D.C.

Kahn M. L. 1978. "Uranium." Mineral Commodity Summaries. Bureau of Mines, Washington DC.

Kalkwarf, D. R. 1979. Solubility Classification of Airborne Products from Uranium Ores and Tailings Piles. PNL-2870. Pacific Northwest Laboratory, Richland, Washington.

McSweeney, T. I. and J. F. Johnson. 1977. An Assessment of the Risk of Transporting Plutonium Dioxide by Cargo Aircraft. BNWL-2030, Pacific Northwest Laboratory, Richland, Washington.

McSweeney, T. I., R. J. Hall et al. 1975. An Assessment of the Risk of Transporting Plutonium $0 x i d e$ and Liquid Nitrate by Truck. BNWL-1846, Pacific Northwest Laboratory, Richland, Washington.

Mishima J. 1976. "Potential Aerosol Generation Mechanisms from Damaged Packages." IAEA-SR 10/15. Transport Packaging for Radioactive Materials. Vienna.

NCRP, National Council on Radiation Protection and Measurements. 1975. Review of the Current State of Radiation Protection Philosophy. NCRP Report No. 43, Washington, D.C.

Nuclear Fuel. December 12, 1977. p. 11.

Pelto, P. J. and W. L. Purcel1. 1977. MFAULT: A Computer Program for Analyzing Fault Trees. BNWL-2145, Pacific Northwest Laboratory, Richland, Washington.

Rand McNally Standard Highway Mileage Guide No. 10. 1973. Household Goods Carrier's Bureau, Arlington, Virginia.

Rhoads, R. E. et a1. 1978. An Assessment of the Risk of Transporting Gasoline by Truck. PNL-2133, Pacific Northwest Laboratory, Richland, Washington.

Selby, J. M., et al. Considerations in the Assessment of the Consequences of Effluents from Mixed Fuel Fabrication Plants. BNWL-1697, Rev. 1, Pacific Northwest Laboratory, Richland, Washington, p. 78-79, June 1975. 
Slade, D. H., ed. 1968. Meteorology and Atomic Energy, 1968. T1024190, Office of Information Services, U.S. Atomic Energy Commission, Washington, D.C.

Smith, M. L. 1978. "Health Physics Aspect in Case of a Truck Accident Involving a Yellowcake Spi11." Exxon Mineral Company.

Survey of United States Uranium Marketing Activity. 1978. DOE/RA-0006, Department of Energy, Washington, D.C.

Turner, D. B. 1970. Workbook of Atmospheric Dispersion Estimates. PB-191-482, U.S. Department of Health, Education, and Welfare, Cincinnati, Ohio.

U.S. Bureau of the Census. 1967. County and City Data Book, 1967, (A Statistical Abstract Supplement). U.S. Department of Commerce, Washington, D.C.

U.S. Weather Bureau. Climatological Data Summaries. U.S. Department of Commerce, National Climatic Center, Asheville, North Carolina. 

APPENDIX A

TRANSPORTATION RISK ANALYSIS METHODOLOGY 
APPENDIX A

TRANSPORTATION RISK ANALYSIS METHODOLOGY

Four basic steps are followed in the PNL transportation risk analysis methodology (McSweeney 1975) to develop the information required to perform the risk analysis. These four steps are:

- A detailed description of the transportation system, including projected industry characteristics, size and number of shipments, and material characteristics.

- The identification of possible material release sequences, using fault tree analysis.

- The evaluation of the probabilities and consequences of releases, using container failure data and mathematical models that express dispersion and health effects.

- The calculation and evaluation of risk, defined as the product of the probability of a release of material to the environment and the consequences of that release.

These four components, shown graphically in Figure A.1, are described in more detail below. Step numbers correspond to the number shown in the figure.

\section{A. 1 SYSTEM DESCRIPTION}

In this portion of the analysis, the basic information on the shipping system to be analyzed is collected. Most of the information is already available or easily derived. A complete description of the transportation system generally consists of seven steps, which are shown in Figure A.1.

The industry being studied is characterized in Steps 1 and 2 by gathering data on facility locations, industry shipping requirements and shipping destinations. Information on the physical and chemical properties of the material being transported is gathered in Step 3. The shipping packages used and the 


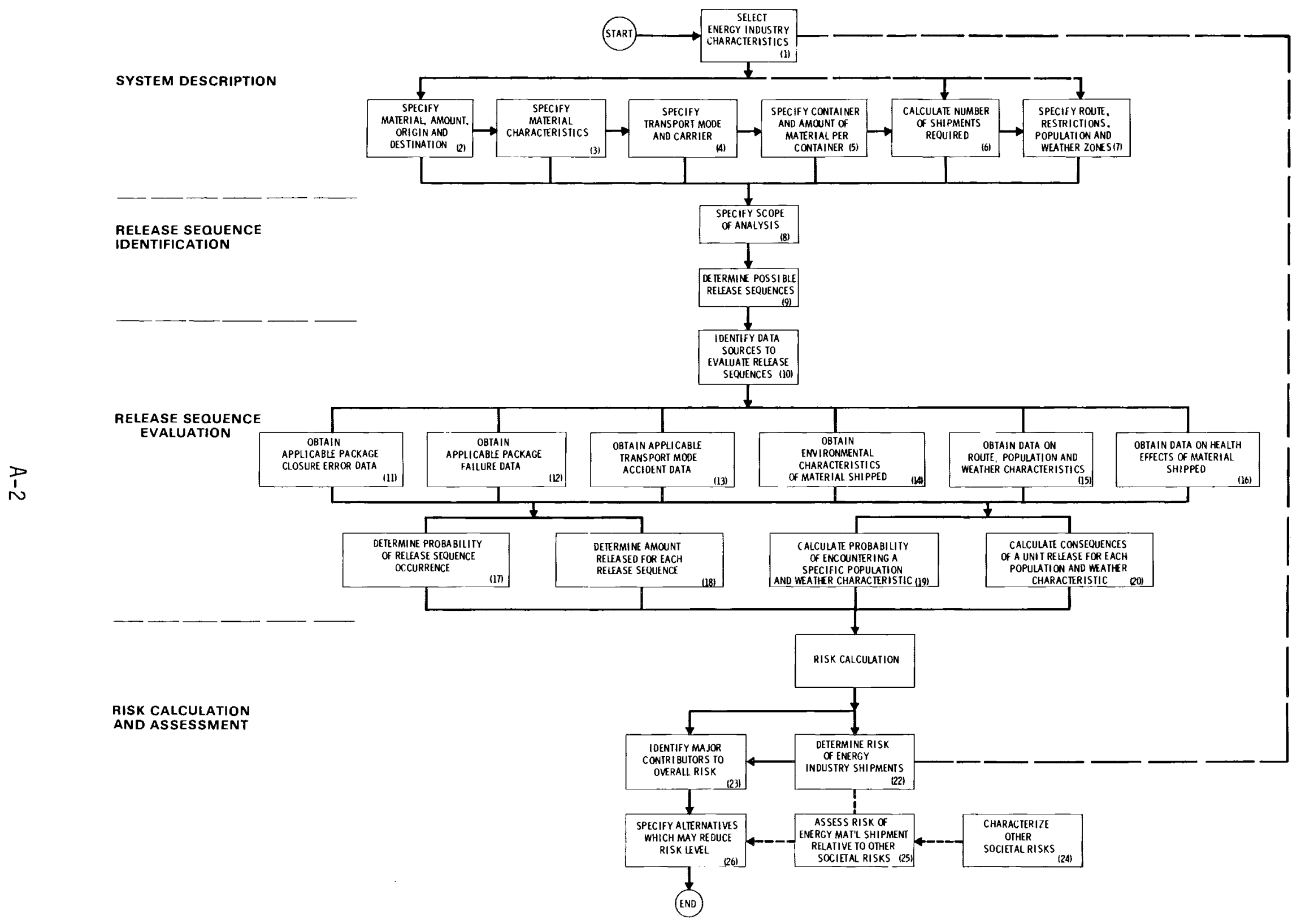

FIGURE A.1. Model to Calculate the Risk of Shipping Energy Materials 
number of packages per shipment are determined in Steps 4, 5 and 6 for each transport mode of interest. In Step 7, the population distributions and weather characteristics along the shipping routes are characterized.

\section{A.2 RELEASE SEQUENCE IDENTIFICATION}

The next component in the risk evaluation process is the identification of the sequences of events that could lead to a release of material from the transport vehicle. This study uses a deductive reasoning process to identify release sequences. Event sequences are identified by assuming that the undesired event has occurred and working backward to identify the sequences of events that must occur to cause this system failure. Fault tree analysis is a formalized way of performing these deductive reasoning processes.

The fault tree analysis technique was developed in the 1960's in the aerospace industry to identify equipment design deficiencies before actual space flight. The procedure assumes a failure and works backwards to identify basic component failures that could cause or contribute to that failure. These failure sequences are also called cut sets. Ideally, the fault tree should be developed to the level of individual components for which failure data are available. In practice, fault trees are seldom developed to that degree. Instead, the fault trees are constructed in terms of basic system modules. Such a fault tree is called a Top Level Fault Tree since it usually identifies only large systems which could result in a failure.

The fault tree can be thought of as a compact notation for identifying and displaying large numbers of release sequences. For larger trees, it is convenient to utilize computer programs, such as the MFAULT code (Pelto 1977), to perform the Boolean algebra that reduces the fault tree to a series of release sequences or "cut sets" required for subsequent steps in the analysis. For simplified fault trees, such as that used in this report, it's relatively easy to identify release sequences by hand.

Before the possible release sequences are identified (Step 9), the scope of the analysis must be delineated (Step 8). Completed studies using this risk evaluation model have considered releases from two general causes. One category 
is releases caused by the forces produced in transportation accidents. The second category is release from a package that is not operating as designed during normal transport. Sources of these releases would include package closure errors, substandard packaging construction or deterioration in packaging condition. The second category has consistently been shown in past studies to be a relatively minor contributor to the system risk. In an effort to concentrate the analysis on the most important failure mechanisms, these sources of release have been excluded from consideration in this particular analysis. Failure associated with deliberate sabotage or diversion attempts has not been considered, but the techniques used in the model are sufficiently general to permit consideration of these events where failure rate (probability) data are available.

\section{A. 3 RELEASE SEQUENCE EVALUATION}

This step consists of two basic parts: 1) estimation of release sequence probabilities and 2) evaluation of the potential consequences of each release sequence.

Release sequence probabilities are obtained by estimating the probability of each of the events that must occur to produce a system failure. This requires historical data and development of information on the response of the shipping system to normal and transportation accident forces (to determine the level of forces required to produce a system failure). A knowledge of the forces present in transportation accidents is also required.

Engineering analysis or data available from testing programs is generally used to determine system failure thresholds (Step 12). This can be combined with accident environment data, such as that developed at Sandia Laboratories (Clarke 1976 and Dennis 1978), or statistical analysis of other accident data to determine failure probabilities (Step 13).

The consequences of a system failure depend on the type of failure that has occurred, the location of the failure along the shipping route and the weather and population conditions at the time of failure. The consequences of the failure sequences may be determined by mathematical modeling of the 
system, from historical accident data and/or from information on tests that have been conducted with the material being shipped. In general, consequences must be evaluated for each type of failure that can occur for each combination of weather condition and population distribution that can be encountered along the route. The probability of encountering the various population distributions and weather conditions along the route must also be determined.

The environmental behavior characteristics and health effects are specific to the material being shipped (Steps 14 and 16). Data for population and weather characteristics (Step 15) are available from U.S. Census data (U.S. Bureau of the Census 1967) and summaries of regional weather data compiled by the U.S. Weather Bureau.

\section{A.4 RISK CALCULATION AND ANALYSIS}

The final component in the risk analysis is to calculate the risk for each specific release sequence and to sum and evaluate the risk associated with all applicable release sequences. The steps involved in this component are shown graphically in Figure A.1. Release sequence risks are added to determine the risk associated with individual shipping routes, which are weighted according to the amounts being shipped along each route. The overall transportation risk (total risk) is the sum of the weighted risks from these routes.

The results are then analyzed to determine the primary contributors to the risk (Step 23) and to specify and evaluate alternatives that could reduce the system risk, if the current risk is judged by society to be unacceptable. Since the information to perform the risk analysis has been developed in discrete data blocks, sensitivity studies can also be carried out to test the effect on the system risk of assumptions and approximations that were made to develop key pieces of information. This may identify areas where further analysis is required or delineate the rimitations of the evaluation. 


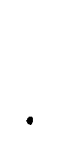


APPENDIX B

URANIUM ORE CONCENTRATE SHIPPING SYSTEM DESCRIPTION 
APPENDIX B

\section{URANIUM ORE CONCENTRATE SHIPPING SYSTEM DESCRIPTION}

Uranium concentrate is classified as a low specific activity material (LSA) according to the Department of Transportation Hazardous Materials Regulations and can be shipped with a minimum of special handling. The material, if shipped in an exclusive use vehicle, is exempt from specification packaging, marking and labeling, although materials must be packaged in strong, tight containers. The containers must also be braced so as to prevent shift of lading under normal transportation conditions.

\section{B. 1 URANIUM ORE CONCENTRATE SHIPPING CONTAINERS}

The uranium ore concentrate shipping system consists of fifty Department of Transportation specification $17 \mathrm{H}, 210$ \& (55-gallon) steel drums carried in a van-type trailer. Each drum has a removable head consisting of a lid and boltlocking ring closure (see Figure B.1). The sides and bottom of the drum are made of 18-gauge low carbon sheet steel and the lid is made of 14-gauge low carbon sheet stee1. The bolted ring is made of 12-gauge low carbon steel with drop forced lugs, with a $1.6 \mathrm{~cm}$ (5/8-inch) bolt and nut. Each drum has three rolling hoops rolled into the body, one of which is near the top curl. Inside dimensions are $0.572 \mathrm{~m}$ (22.5 in.) ID $\times 0.845 \mathrm{~m}$ (33.25 in.) height and external dimensions are $0.610 \mathrm{~m}(24.0 \mathrm{in.})$ OD $\times 0.889 \mathrm{~m}(35.0 \mathrm{in.})$ height. The gasket material for the top closure must have a minimum operating range of $-40^{\circ} \mathrm{C}\left(-40^{\circ} \mathrm{F}\right)$ to $57^{\circ} \mathrm{C}\left(+130^{\circ} \mathrm{F}\right)$. Tare weight of each drum is assumed to be $18 \mathrm{~kg}(40 \mathrm{lb})$.

Each drum is assumed to contain $363 \mathrm{~kg}$ (800 1b) of yellowcake (uranium ore concentrate). The fifty drums are loaded, standing on end, into a conventional, general commodity, van-type trailer. Drums are assumed to be arranged in the trailer in two groups of twenty-five each to concentrate the weight over the trailer axles, as shown in Figure B.2. Wood $2 \times 4$ 's are nailed to the floor of the trailer as shown to prevent shifting of the drums during normal transport. Distance between the two groups is assumed to be $6 \mathrm{~m}(20 \mathrm{ft})$. 


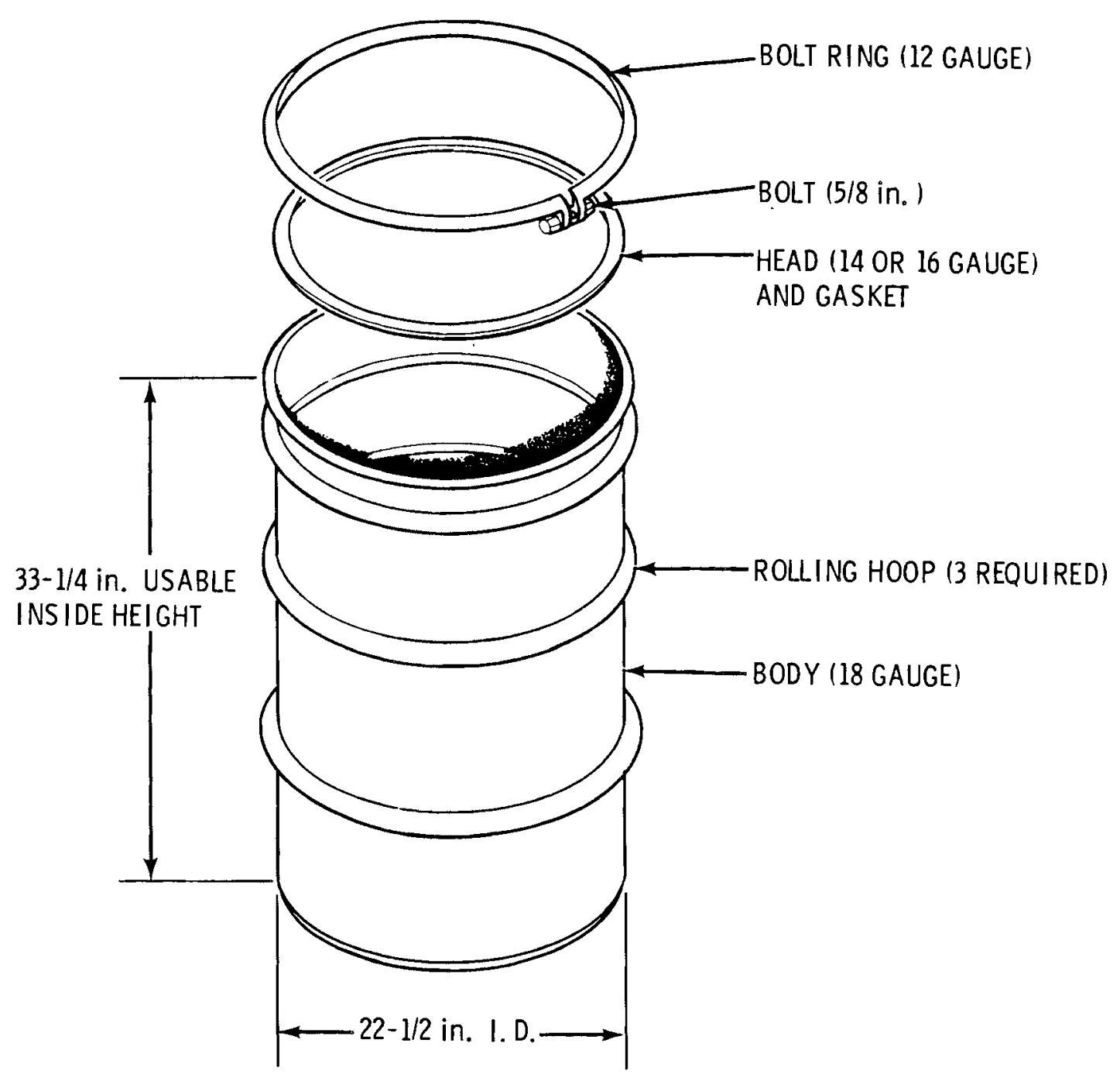

FIGURE B.1. Department of Transportation Specification 17H Steel Drum

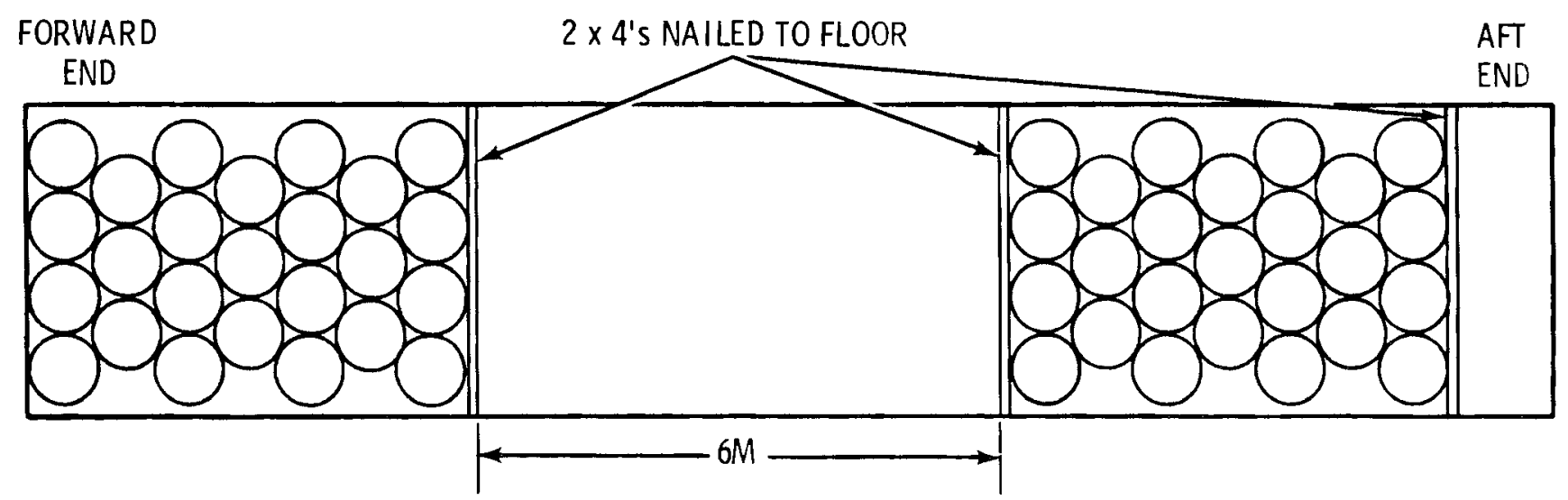

FIGURE B.2. Configuration of Drums in Semi-Trailer 


\section{B.2 URANIUM ORE CONCENTRATE MATERIAL PROPERTIES}

Uranium concentrate is produced from uranium ore in a milling process. The ore is first crushed and ground, and then leached with sulfuric acid or sodium carbonate-bicarbonate. A series of separation steps then follow. The final product is a powder that is usually canary-yellow in color, although it may range from olive green to black. The consistency of the product ranges from granular to a fine, flour-like powder. The exact composition of this product, commonly called yellowcake, is variable, depending on the precipitating conditions in the milling process. However, most concentrates average about $80 \%$ uranium compounds. of the other $20 \%$ of product, about 3 to $5 \%$ is water, 3 to $4 \%$ is sulfur, and the rest is comprised of various rock compounds.

Because of the variable composition of yellowcake, specific chemical properties for the ore concentrates are not available. However, the properties for pure $\mathrm{U}_{3} \mathrm{O}_{8}$ wil1 represent a maximum limit, and are used for the purpose of this analysis. The ore concentrates decompose before reaching a melting point. The material will not burn.

In estimating the hazard from airborne releases, it is important to know the particle sizes of the concentrate. Particles less than 10 microns in diameter can be inhaled and enter the bronchial system. Two yellowcake samples were aerodynamically sized using sedimentation methods. The resulting data are in Table B. 2 and Figure B.3, showing that $18 \%$ and $32 \%$ weight percent of the source material was in the size fraction less than 10 microns. For the purposes of this study, an average value of $25 \%$ was thus used as the fraction of the yellowcake shipment that is of respirable size particles. This fraction was used in determining the health effects from a yellowcake release. 
TABLE B.2. Yellowcake ${ }^{(a)}$ Particle Size Distribution

\begin{tabular}{|c|c|c|c|c|}
\hline \multirow{2}{*}{$\begin{array}{l}\text { Size } \\
(\mu \mathrm{m})\end{array}$} & \multicolumn{2}{|r|}{ Mill 1} & \multicolumn{2}{|c|}{ Mil1 2} \\
\hline & (g) & (\% of total) & (g) & of total) \\
\hline$<$ & 2.6 & 10 & 1.8 & 5 \\
\hline $1-3$ & 2.2 & 9 & 1.8 & 5 \\
\hline $3-7$ & 2.3 & 9 & 1.1 & 3 \\
\hline $7-13$ & 3.0 & 12 & 6.7 & 18 \\
\hline $13-18$ & 1.6 & 6 & 3.5 & 9 \\
\hline $18-44$ & 12.4 & 48 & 22.1 & 58 \\
\hline$>44 \mu \mathrm{m}$ & 1.5 & 6 & 0.8 & 2 \\
\hline
\end{tabular}

(a) Yellowcake - mill products ready for shipment.

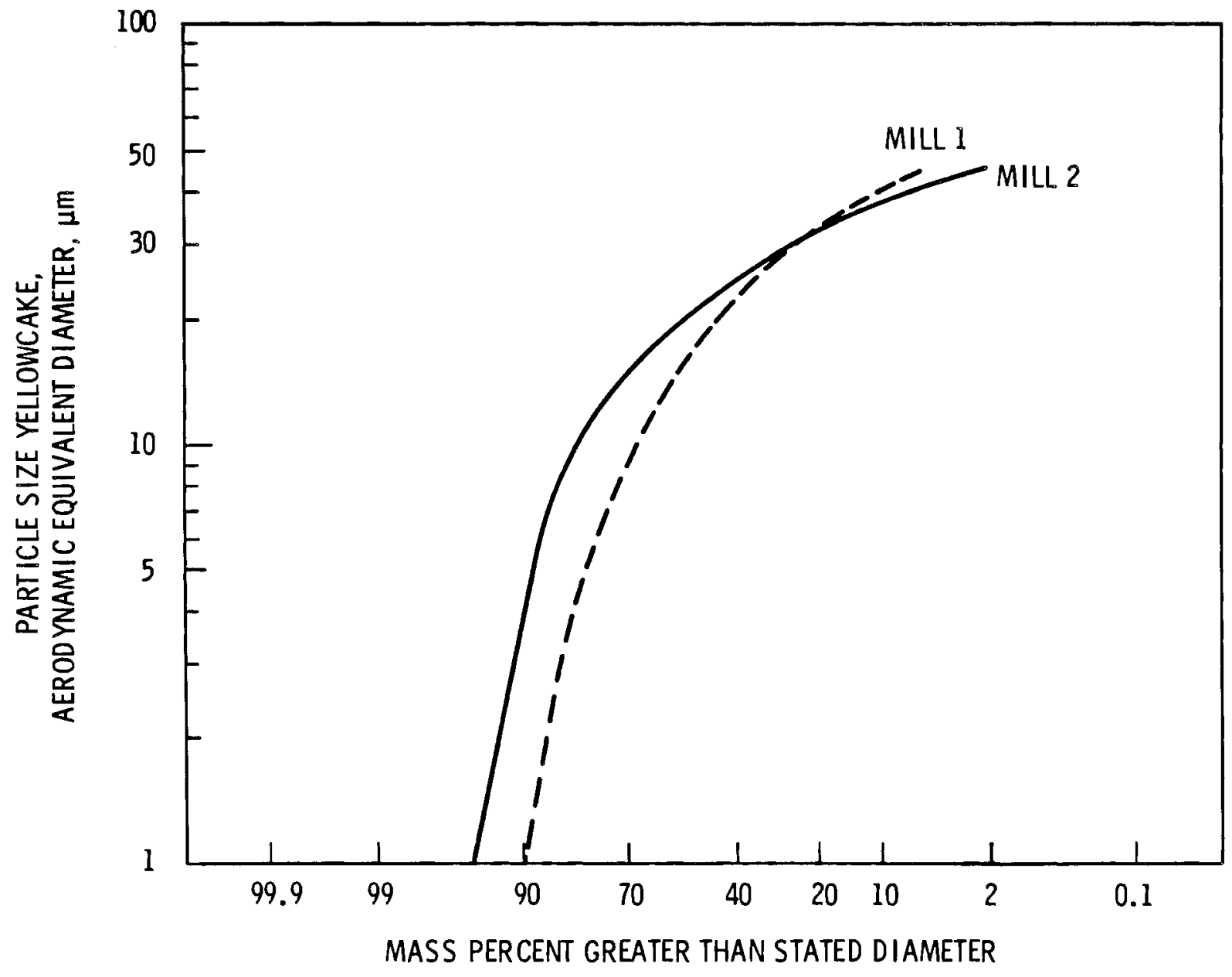

FIGURE B.3. Yellowcake Particle Size Distribution 


\section{APPENDIX C}

RELEASE SEQUENCE PROBAB IL IT IES 
APPENDIX C

\section{RELEASE SEQUENCE PROBABILITIES}

The information presented in this Appendix was used to derive the frequency of occurrence values for the release sequences identified in Section 4.1. Estimation of release sequence probabilities primarily requires knowledge of the forces or stresses that may be generated in a truck accident, and the level of applied stress that will result in container failure and a release of material to the environment. Section C.I presents the results of structural analys is on the yellowcake containers. Failure of a container during an accident occurs when the forces generated exceed the mechanical strength of the container affected. For this analysis, the stresses present in a truck accident include fire, puncture, immersion, impact and crush. Section C.2 describes the basic event probabilities for each event described in the yellowcake transportation fault tree. Information on accident environments was developed by Sandia Laboratories (Clarke 1976).

\section{1 FAILURE THRESHOLD DETERMINATION FOR URANIUM ORE CONCENTRATE DRUMS}

The uranium ore concentrate shipping system was analyzed to obtain package failure thresholds for fire, impact and crush accidents, as well as the thresholds for puncture and immersion accidents. The failure threshold for a container is the level of applied stress that will result in container failure and a release of material to the environment.

Two fire accident scenarios were considered: 1) a $1010^{\circ} \mathrm{C}$ fire surrounding the entire trailer and drums in their normal shipping configuration; and 2) a single drum exposed to a $1010^{\circ} \mathrm{C}$ fire, simulating the failure of a single drum which had exited the trailer. Failure of the yellowcake drums due to fire was calculated to be unlikely for fires of reasonable length.

The impact accident considered for the purpose of structural failure threshold calculations was that of a single drum escaping the trailer and impacting onto a rigid surface. In an actual accident, more than one drum will most likely fail by impact forces. However, the failure threshold should be the same for each drum. 
Failure as a result of impact forces was calculated not to occur for impact velocities of less than an equivalent 1.2-m drop height.

The crush accident scenario analyzed is one where the trailer is decelerated and the drums inside are subjected to inertial crush. The range of allowable crush forces for the drums was determined as well as the number of drums to fail due to inertial crush as a function of trailer deceleration.

\title{
C.1.1 Fire
}

The single drum accident simulates a drum that exits the trailer during an accident, remains essentially intact, and then is exposed to the fire. The drum could possibly fail due to exposure to the fire by the stresses in the drum exceeding the tensile strength of the steel. Stresses in the steel could be created by internal pressurization from the water in the yellowcake turning to steam, or by thermal stresses from temperature gradients.

To assess the possible failure mechanisms, the thermal response of the drum and yellowcake to the $1010^{\circ} \mathrm{C}$ fire was needed. To obtain this, the drum and yellowcake were modeled using the HEATING4 code. HEATING4 is a finite difference heat conduction code designed to solve steady-state and/or transient heat conduction in one-, two-, or three-dimensional Cartesian or cylindrical coordinates (HEATING3, 1971). The grid for the 2-D quarter section mode 1 that was used for the analysis is shown in Figure C.1. Thermal radiation to all external surfaces from a $1010^{\circ} \mathrm{C}$ black body was assumed. Convection was ignored. The absorptivity and emissivity of the drum were assumed to be 0.8 (Handbook of Tables 1970). Since the drum wall is fairly thin and the conductivity of the steel is much greater than that assumed for the yellowcake, the steel was ignored in the anaiysis. The steel was treated as a thermal short to the outside surface of the yellowcake and to have the same temperature as the outside of the yellowcake. The absorbtivity and emissivity of the surface was that for steel. The yellowcake properties assumed for the analysis are:

\author{
Thermal Conductivity $=0.00078 \mathrm{Cal} / \mathrm{sec}-\mathrm{cm}{ }^{\circ} \mathrm{C}$ \\ Density $=1520 \mathrm{~kg} / \mathrm{m}^{3}$ \\ Heat Capacity $=0.22 \mathrm{Cal} / \mathrm{gm}^{\circ} \mathrm{C}$
}


The temperature response for several places in the steel and yellowcake are shown in Figure C.2. The points $A$ through $E$ are those labeled in Figure C.1. Points $A$ and $B$ are on the steel and Points $C, D$ and $E$ are in the yellowcake. As can be seen from Figure C.2, the surface of the drum heats up very quickly. After only one minute, the drum surface is already over $450^{\circ} \mathrm{C}$ and after 5 minutes the surface is over $950^{\circ} \mathrm{C}$. The temperature of the steel increases very uniformally, except for the corner near the ring closure. This point is subject to radiation from both the top and side and is, therefore, slightly hotter. The interior of the yellowcake heats up much slower than the steel. The temperature at Point $A$ in the yellowcake halfway between the surface and the yellowcake center only increases by about $2^{\circ} \mathrm{C}$ in one hour. A large temperature gradient in the yellowcake is evident when the temperatures at Points $A$, $C$ and $D$ are compared. If the value of the yellowcake thermal conductivity is higher than the assumed value, the interior of the yellowcake would heat up faster than this analysis indicates. However, the thermal response of the steel drum would not be significantly changed. Since the yellowcake does not melt or decompose at less than $1600^{\circ} \mathrm{C}$, and will not burn, failure is determined by the loss of integrity of the steel drum. Increases in the yellowcake temperature may increase the internal pressure in the drum as the contained water turns to steam.

A possible failure mechanism of the drum during the fire is the stress in the drum exceeding the tensile strength of the steel. The tensile strength of the stee 1 in the neighborhood of $1000^{\circ} \mathrm{C}$ is greatly reduced from its room temperature value. The only available data that we were able to find was for low carbon steel up to $815^{\circ} \mathrm{C}$. As can be seen in Figure C.3, even at $815^{\circ} \mathrm{C}$ the tensile and yield strengths are very low. Extrapolation of the data to $1010^{\circ} \mathrm{C}$ does not appear reasonable since the yield strength would be negative. If we assume that the tensile strength decreases linearly from $815^{\circ} \mathrm{C}$ to the melting point of $1515^{\circ} \mathrm{C}$, a value for the tensile strength of $9580 \mathrm{kN} / \mathrm{m}^{2}(1390 \mathrm{psi})$ is obtained. In the absence of better data, this value is used.

Three possible causes of stresses in the wall are possible. These are internal pressurization due to the water turning to steam; thermal gradients in the steel; and hydrostatic pressures from the yellowcake. Pressurization of the drum 


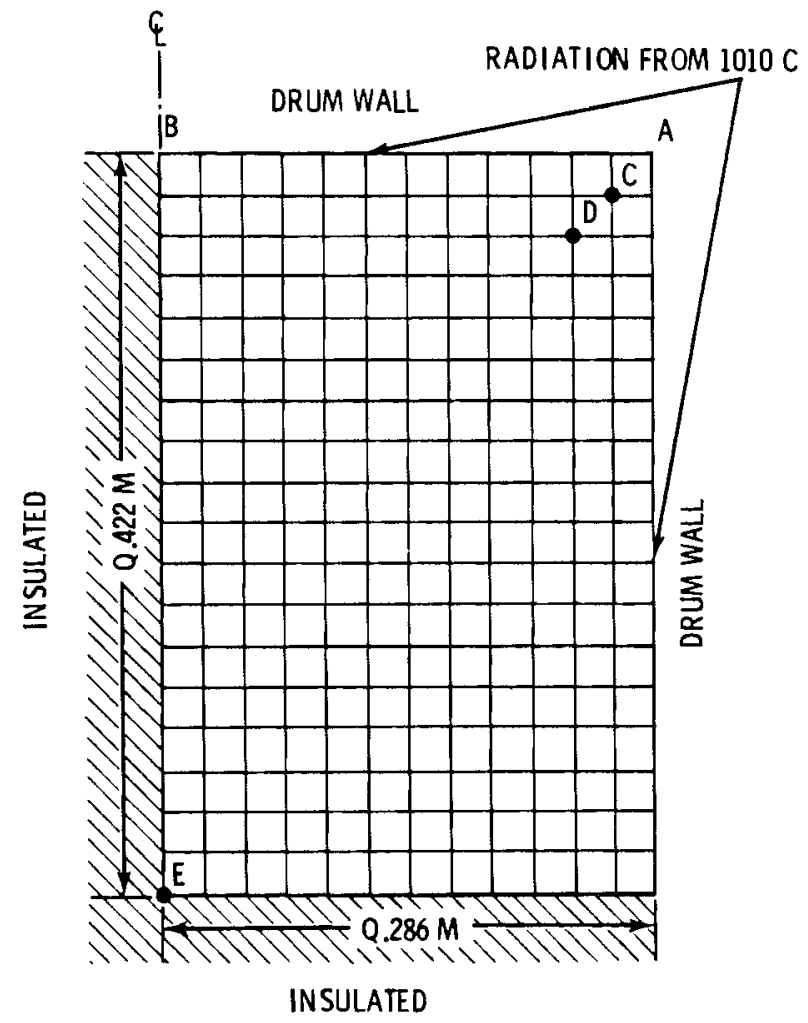

FIGURE C.1. Grid Used for 2-D, Quarter Section HEATING4 Model of Drum and Yellowcake

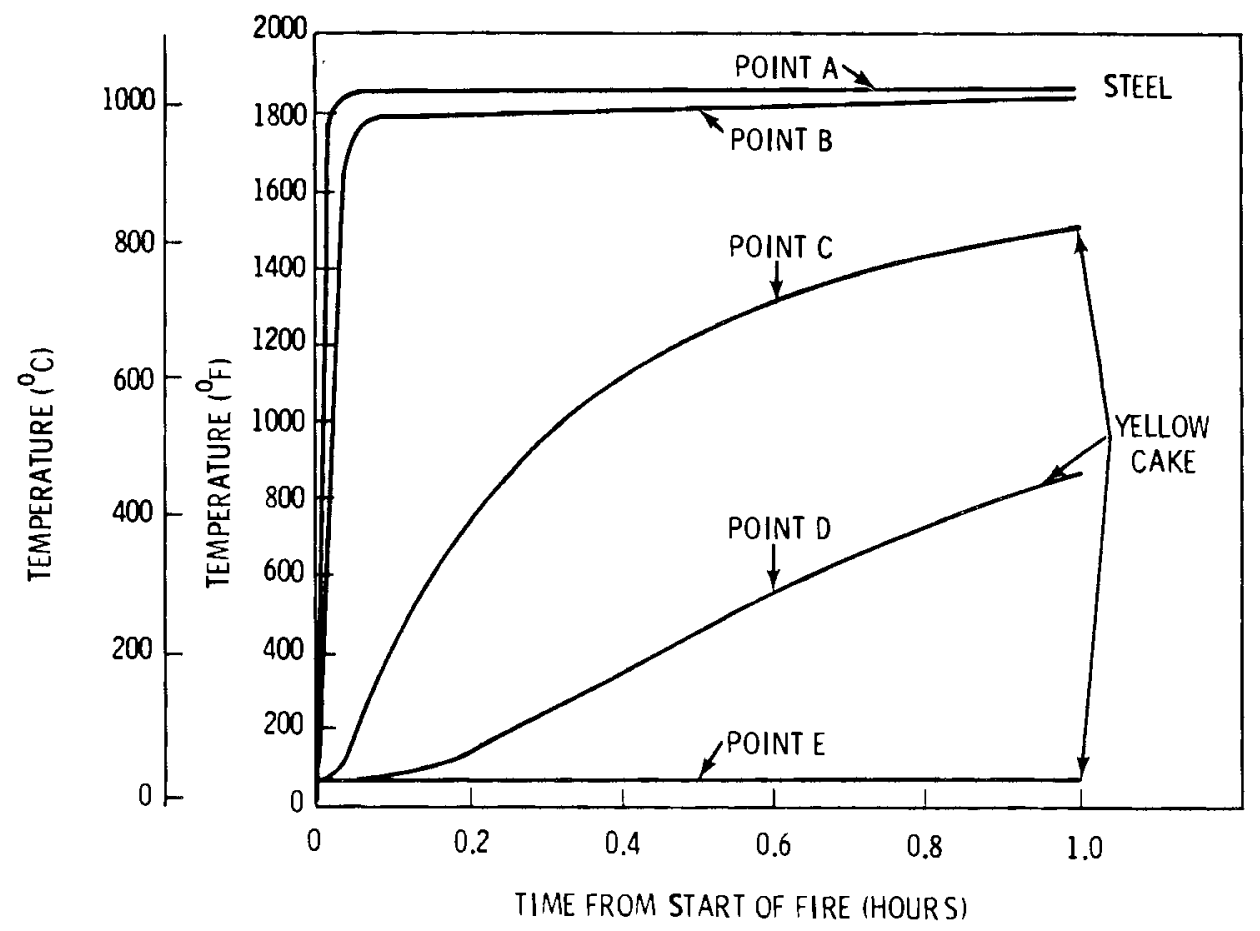

FIGURE C.2. Temperature Response of Yellowcake Drum 

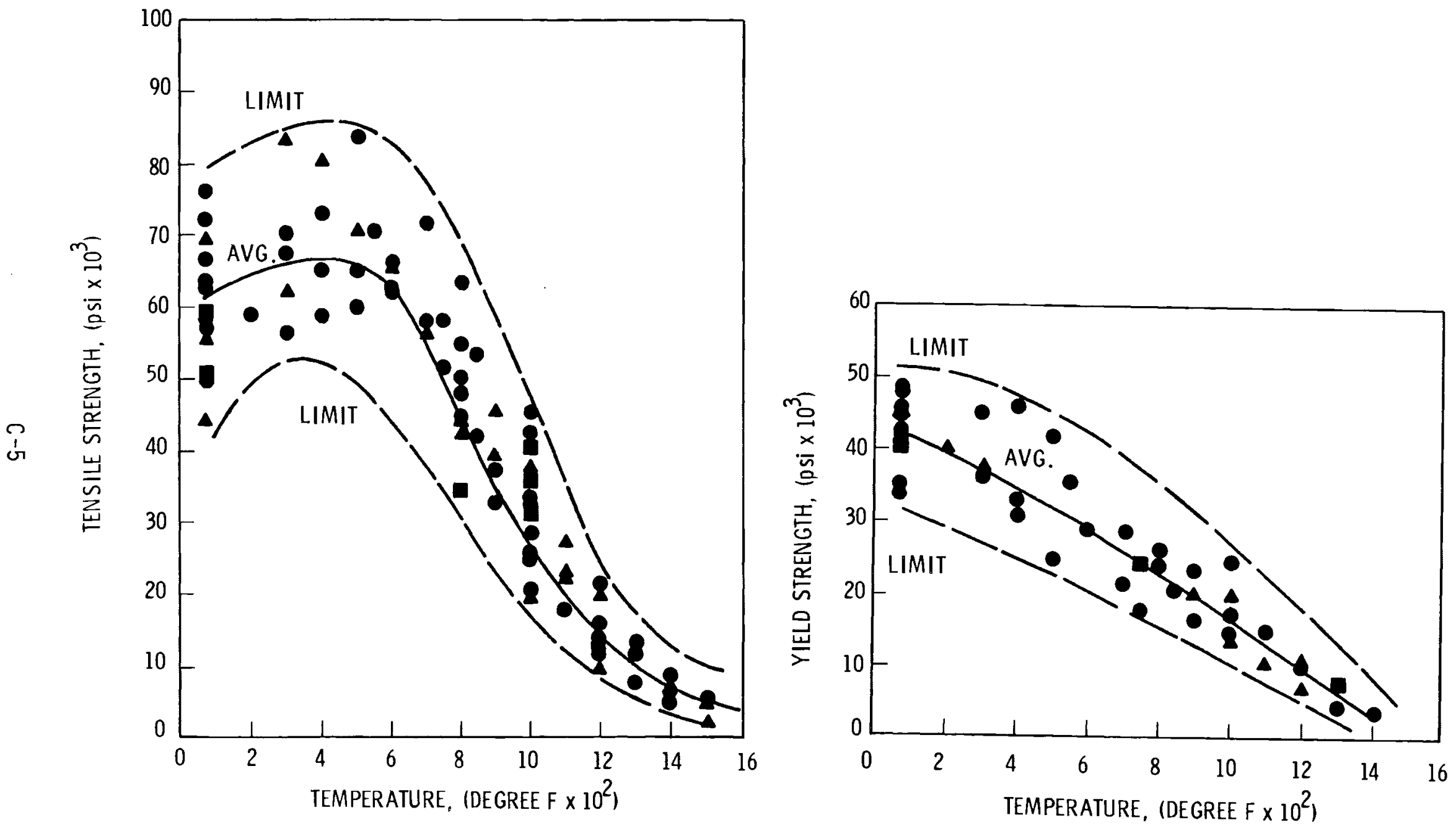

FIGURE C.3. Temperature Dependent Tensile and Yield Strength of Low Carbon Steel ( $1 \mathrm{psi}=6.9 \mathrm{kN} / \mathrm{m}^{2}$ ) Source: American Society for Testing Materials, Report on the Strength of Wrought Steels at Elevated Temperature, Special Technical Publication No. 100, 1950. 
from steam will not be possible since this would require the lid gasket to be subjected to temperatures greatly exceeding its operating range. The failure of the lid gasket would allow the escape of moisture from the yellowcake container in the form of steam. The yellowcake itself, however, will remain inert. It is not entrained in the steam or air flow, and will require a more catastrophic drum failure to enable a material release. Since the surface of the drum will heat fairly uniformly during the fire, stresses due to thermal gradients will not be severe. Even if thermal stresses greater than the yield strength occur, the steel would yield locally and limit these stresses. Thus, thermal stresses will not cause drum failure. The maximum stresses in the drum due to the hydrostatic. pressure of the yellowcake can be conservatively approximated as:

$$
\sigma=\frac{P R}{t}=\frac{\rho h R}{t}=3280 \mathrm{kN} / \mathrm{m}^{2}
$$

where:

$$
\begin{aligned}
& \sigma=\text { stress } \text { in drum } \\
& P=\text { hydrostatic pressure } \\
& R=\text { drum radius } \\
& t=\text { wall thickness } \\
& \rho=\text { density of water } \\
& h=\text { height of drum }
\end{aligned}
$$

Even if the drum had been in the fire for an hour and had 1ost $18 \%$ of its wall thickness from each side due to scaling, the predicted stress was found to be only $5120 \mathrm{kN} / \mathrm{m}^{2}$ (743 psi). This is only slightly over half of the tensile strength that we postulated for a temperature of $1010^{\circ} \mathrm{C}$. Therefore, failure of the drums due to temperature induced stresses does not appear likely.

Since the analysis of the single drum exposed to the $1010^{\circ} \mathrm{C}$ fire did not indicate a failure of the drum, the exposure of the entire trailer to a fire is not likely to cause drum failures. The amount of heat transfer to each drum is lower because of shielding by the van or trailer wall and by shielding of the inner drums by the outer drums. 


\section{C.1.2 Impact}

The impact accident consists of a single fully loaded drum impacting an essentially unyielding surface. Since the surface is rigid, all of the kinetic energy dissipated during the impact is due to deformation of the drum and contents. The crush energy required to fail a standard Rule 40 drum is given as 2730 joules (Colton 1978). A Rule 40 drum is almost identical to a Specification $17 \mathrm{H}$ drum except for the size of the bolt used in the ring closure. Since the failure of the Rule 40 drums was not by bolt failure and the Specification $17 \mathrm{H}$ drum has a larger bolt, the Rule 40 data can be expected to be valid for our analysis. The impact velocity, $v$, required to produce failure can be approximated by equating the kinetic energy of the drum before impact, $1 / 2 \mathrm{~m} v^{2}$, to the energy absorbed by the drum, $E_{\text {crush }}$.

$$
E_{\text {crush }}=1 / 2 \mathrm{mv}^{2}
$$

or

$$
v=\sqrt{\frac{2 E_{\text {crush }}}{m}}=3.8 \mathrm{~m} / \mathrm{sec}
$$

This corresponds to a drop height of $0.73 \mathrm{~m}$. Edling (1975) states that a $1.22 \mathrm{~m}$ free drop test of a $210-\ell$ Specification $17 \mathrm{H}$ drum onto a flat essentially unyielding horizontal surface was conducted without drum failure. Drum weight was $382 \mathrm{~kg}$. This is a definite indication that the above assumptions and calculations are very conservative. This is probably due to the fact that strain rate effects of the impact bear significantly on the results. The drop test data (Edling 1975) is thus more meaningful than the energy to failure calculations.

\section{1.3 Crush}

Crush is compression caused by relatively long time (>>10 msec) loading on a package as a result of inertial loadings from other cargo in the trailer. Colton (1978) contains data on crush tests conducted on standard Rule 40 drums which are, at least for the purposes of this analysis, almost identical to the Specification $17 \mathrm{H}$ drums. In order to simulate drums filled with yellowcake, 
several drums were filled with sand before the crush tests. Failure crush forces for these drums ranged from $7700 \mathrm{~kg}$ to $9525 \mathrm{~kg}$.

Inertial forces during a crush accident are caused by the deceleration of the trailer during a collision. For our analysis, the walls of the trailer are assumed to experience no gross deformation. The deceleration of the trailer is assumed constant during the accident. The crush loads are assumed to be transmitted in the direction of travel only. These assumptions are similar to those used in (Clarke 1976).

The crush force that each drum experiences is a function of the drum's location. Crush forces near the front of the trailer are higher than near the back. The drums in rows with only three drums are subjected to higher loads than those in rows with four drums. Because deformation of the drums is important, the assumption of rigid cylinders is not accurate. Most of the kinetic energy in the drums is dissipated by the plastic deformation of the drums. In order to simulate the energy dissipation during a trailer deceleration, a onedimensional, large displacement, dynamic, finite element model of the system was prepared using ADINA, which is a general purpose dynamic, large displacement finite element code (ADINA 1976). Each row of drums in the trailer was simulated by a single elastic-plastic truss element. The compressive force in each drum of a row was assumed the same. Figure C.4 shows a typical load deflection curve (Colton 1978). The dashed line shows the approximation that was used in the computer model. Two different approaches were used to handle the two separate groups of drums. In the first approach, the rear group of drums was assumed to be situated up tight against the front group. In the second approach, the rear group of drums was initialiy $6 \mathrm{~m}$ (20 ft) away from the front group. The rear group was assumed to experience no deceleration until it had silid forward into the front group. The $2 \times 4$ 's were assumed to offer no resistance. The maximum compressive force obtained for each drum as a function of its row is shown in Figure C.5. This plot is for a $2.3 \mathrm{~g}$ deceleration of the trailer. As can be seen, the results of the two approaches were very similar, especially for the front group of drums where the forces are highest. For purposes of determining the failure threshold, the maximum compressive force of either the one or two group analysis was used. Using the finite 


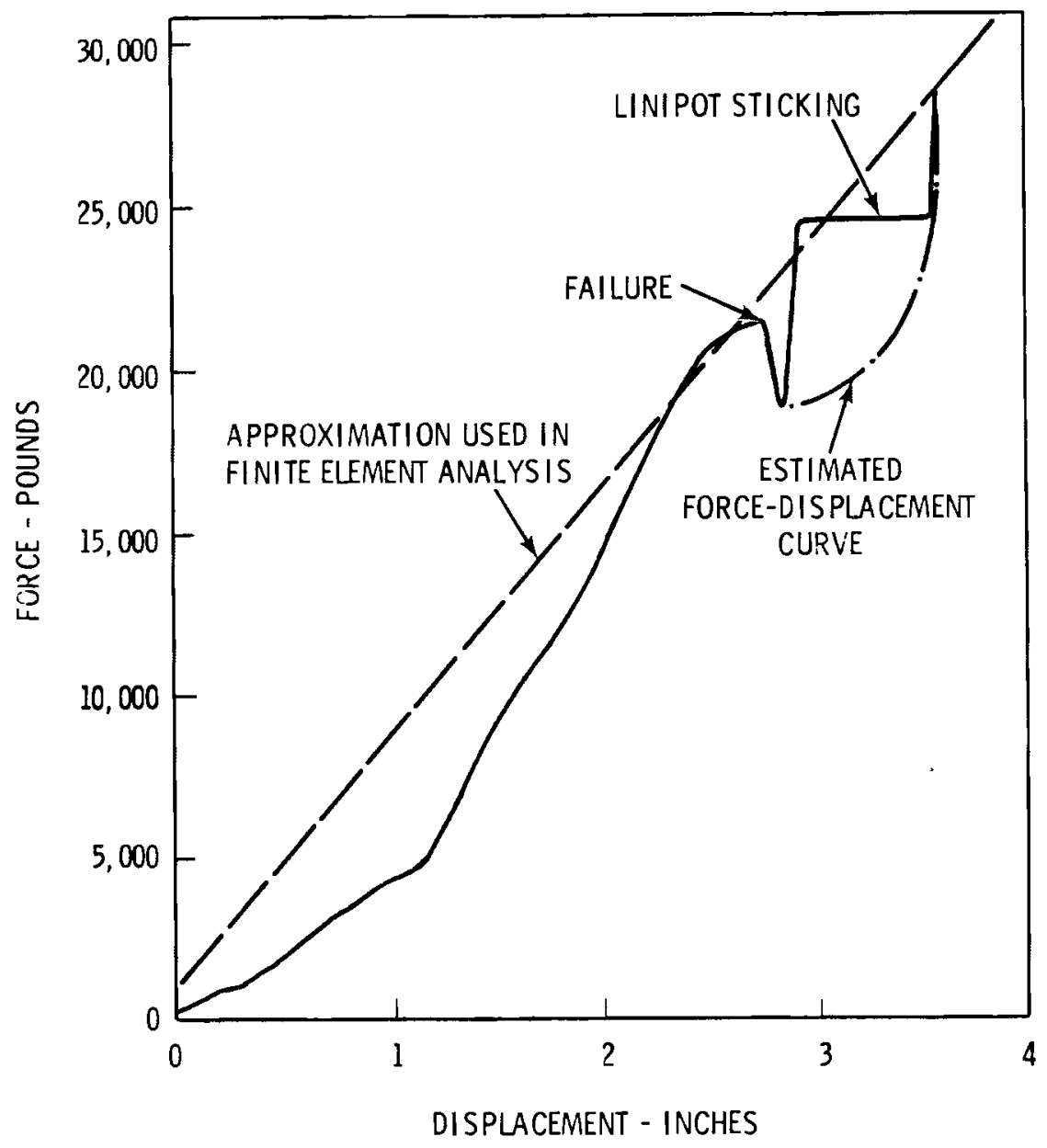

FIGURE C.4. Crush Force Versus Displacement (Source: Colton 1978) 1 pound $=4.45 \mathrm{~N}$

1 inch $=2.54 \mathrm{~cm}$

element results, it is possible to predict the value of trailer deceleration at which each row of drums will fail. The failure point was defined as being reached when the maximum compressive force was greater than $9525 \mathrm{Kg}$. Figure $\mathrm{C} .6$ shows the number of drums predicted to fail as a function of the trailer deceleration.

\section{C.1.4 Puncture}

Puncture is defined as penetration of the drum wall upon striking or being struck by an object. The penetrating object could be part of the deformed trailer or some external object which pierces the trailer wall. 


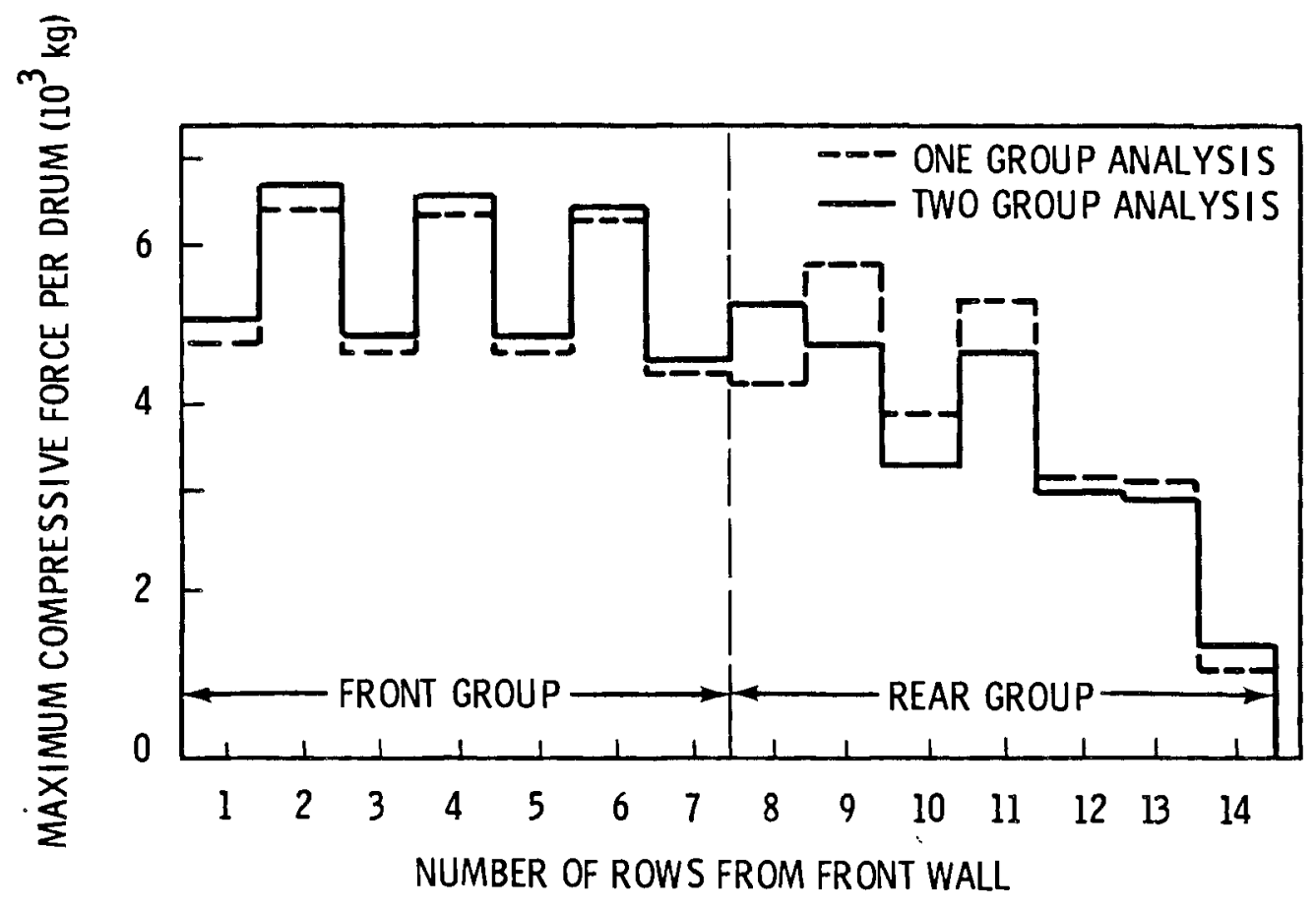

FIGURE C.5. Dynamic Finite Element Predictions of Drum Crush for $2.3 \mathrm{~g}$ Deceleration of Trailer

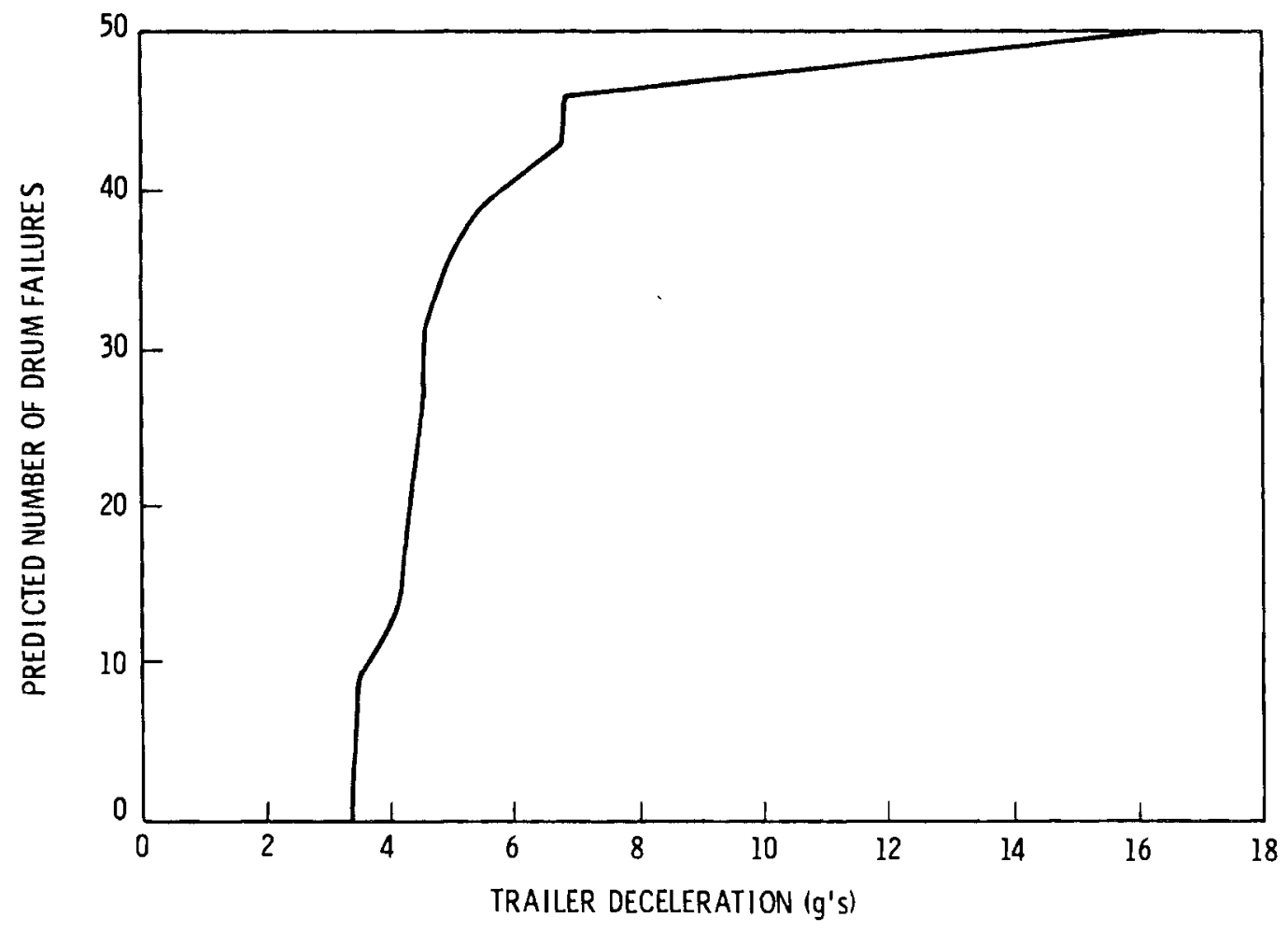

FIGURE C.6. Drum Failures Versus Trailer Deceleration 
Goldsmith (1960) states that the total mechanical work performed by a conical projectile piercing a plate is

$$
w=\pi h_{0} R^{2} \rho\left(V_{1} R / L\right)^{2}+\sigma_{y} / 2
$$

where

$$
\begin{aligned}
W & =\text { work performed } \\
h_{0} & =\text { plate thickness } \\
R & =\text { maximum radius of projectile } \\
\rho & =\text { density of plate } \\
V_{1} & =\text { relative velocity } \\
L & =\text { projectile length } \\
\sigma_{y} & =\text { yield strength of plate }
\end{aligned}
$$

For reasonable accident velocities, the first term in the brackets is negligible compared to $\sigma_{y} / 2$. Therefore, equating the kinetic energy of the drum to the work

$$
1 / 2 m v^{2}=1 / 2 \pi h_{0} R^{2} \sigma_{y}
$$

or

$$
\frac{V}{R}=\sqrt{\frac{\pi h_{0} \sigma_{y}}{m}}=59.93 / \mathrm{sec}
$$

where

$$
\begin{aligned}
\sigma_{y} & =358,500 \mathrm{kN} / \mathrm{m}^{2}(52,000 \mathrm{psi}) \\
h_{0} & =0.121 \mathrm{~cm}(0.0478 \mathrm{in}) \\
m & =31.7 \mathrm{~kg}\left(2.17 \mathrm{lb}-\mathrm{sec}^{2} / \mathrm{in}\right)
\end{aligned}
$$

Therefore, if a probe radius is assumed, the velocity required to puncture the drum is

$$
V=59.93 \mathrm{R} / \mathrm{sec}
$$




\section{1.5 Immersion}

Immersion is defined as submersion of a package in a liquid medium, most frequently water. The criterion used to define the immersion threat is the depth of water in which the package is located.

If the drum is treated as a thin cylindrical shel1, the collapse pressure (Timoshenko 1961) is

${ }^{9} C R=\frac{E h}{a} \frac{1}{n^{2}+1 / 2(\pi a / l)^{2}}\left\{\frac{1}{n^{2}(l / \pi a)^{2}+1^{2}}+\frac{n^{2}}{12 a^{2}\left(1-\nu^{2}\right)} n^{2}+\frac{\pi a^{2}}{e}{ }^{2}\right\}$

where

$$
\begin{aligned}
& \mathrm{E}=\text { Young's modulus }=2.1 \times 10^{8} \mathrm{kN} / \mathrm{m}^{2}\left(30 \times 10^{6} \mathrm{psi}\right) \\
& \mathrm{h}=\text { drum wall thickness } \\
& \mathrm{a}=\text { drum radius } \\
& l=\text { drum length } \\
& \nu=\text { Poisson's Ratio }=0.3 \\
& \mathrm{n}=\text { integer that makes this expression a minimum }
\end{aligned}
$$

For the yellowcake drum the value for $a_{C R}$ is calculated to be $77 \mathrm{kN} / \mathrm{m}^{2}(11.17 \mathrm{psi})$, which is equal to $7.8 \mathrm{~m}(25.8 \mathrm{ft})$.

\section{C.2 BASIC EVENT PROBABILITIES}

The expected frequency of each release sequence devloped in the fault tree is obtained by taking the product of the probability of each event in the sequence. The estimates of the basic event probabilities are presented below. Accident Occurs (XI)

The accident rate for truck transport is $1.55 \times 10^{-6}$ truck accidents per kilometer (Clarke 1976). This rate was based on accident frequency data prepared by the Bureau of Motor Carrier Safety of the U.S. Department of Transportation and is the basis for the Sandia accident environment data. The average shipping distance for uranium ore concentrates is 2660 kilometers (see Section 3 ). The expected accident frequency for uranium ore concentrate shipments, then, is $4.12 \times 10^{-3}$ accidents per shipment. This value is used in the analysis. 
Container (Yellowcake Drum) Failed by Fire (X2)

Information on the fire environment for an accident involving a truck carrying uranium ore concentrates is taken from information developed at Sandia Laboratories (Clarke 1976). Data from summaries of accident report filed by commerical carriers indicate that fires occur in approximately $1.6 \%$ of all truck accidents. Essentially all of these fires last no longer than an hour. Structural analys is of the yellowcake drums (Section C.1), however, shows that yellowcake containers are not susceptible to failure by fire. Thus, even if a drum is subjected to the fire environment, which is fairly likely, it should not be failed by fire. This failure mechanism was therefore excluded from the remainder of the analysis.

Container (Yellowcake Drum) Failed by Puncture (X3)

Information on the puncture environment experienced by containers in a truck accident is obtained from Sandia Laboratories. The probability of an accident involving a puncture situation, given that an accident has occurred, is shown to be 0.20 (Clark 1976). For packages about the size of a yellowcake drum, about $6.8 \%$ of the drums are expected to be damaged in a puncture accident if the puncture force is above a threshold failure point. The puncture threshold failure for a yellowcake drum is given in Section $C .4$ as a V/R ratio of about 6.0. From Figure C.7, the probability of exceeding this failure threshold is about 0.025 . The probability value for failure of a yellowcake drum by puncture forces is $(0.20)(0.068)(0.025)$, or $3.4 \times 10^{-4}$. This value contains the probabilities of puncture for both retained and ejected containers.

Container (Yellowcake Drum) Failed by Immersion (X4)

Information on the immersion environment experienced in a truck accident is obtained from Sandia Laboratories (Clarke 1976). The probability of experiencing immersion, given that an accident has occurred, is $7.0 \times 10^{-6}$. From the structural analysis of yellowcake drums (presented in Section C.5), an immersion depth of over $7.8 \mathrm{~m}(25.8 \mathrm{ft})$ must be experienced to fail the drums. From Figure C.8, the probability of experiencing a depth greater than $7.8 \mathrm{~m}$, given an immersion accident, is 0.007 . Thus, the total probability of a container being failed by immersion forces, given a truck accident has occurred, is $4.9 \times 10^{-8}$. 


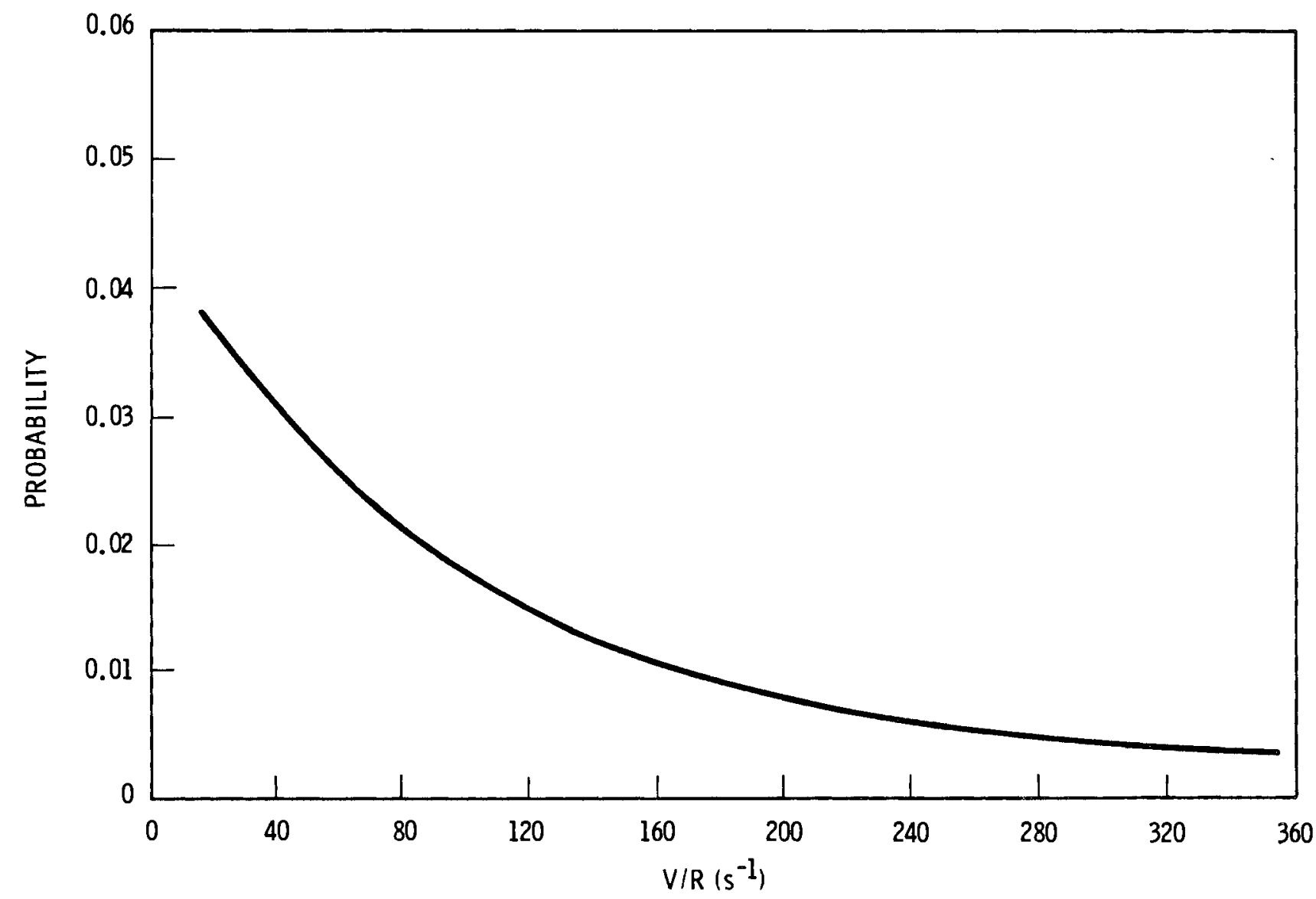

FIGURE C.7. Probability, Given a Puncture Threat, of Exceeding a Specified Value of $V / R$

Impact Forces Produced in Accident (X5)

The impact environment for an accident involving a truck carrying uranium ore concentrates is taken from information developed at Sandia Laboratories (Clarke 1976). The impact environment for the drums is assumed to be present in all collision and overturn accidents. Collisions with other vehicles, trains or stationary objects, or overturn accidents, occur in 89.4 percent of expected truck accidents. The value used for this event is thus 0.894 impacts per accident.

Drums Are Ejected From Van (X6)

In the transportation of uranium ore concentrates, a release of material presents risks to the public only if it is allowed to escape the van. It is 


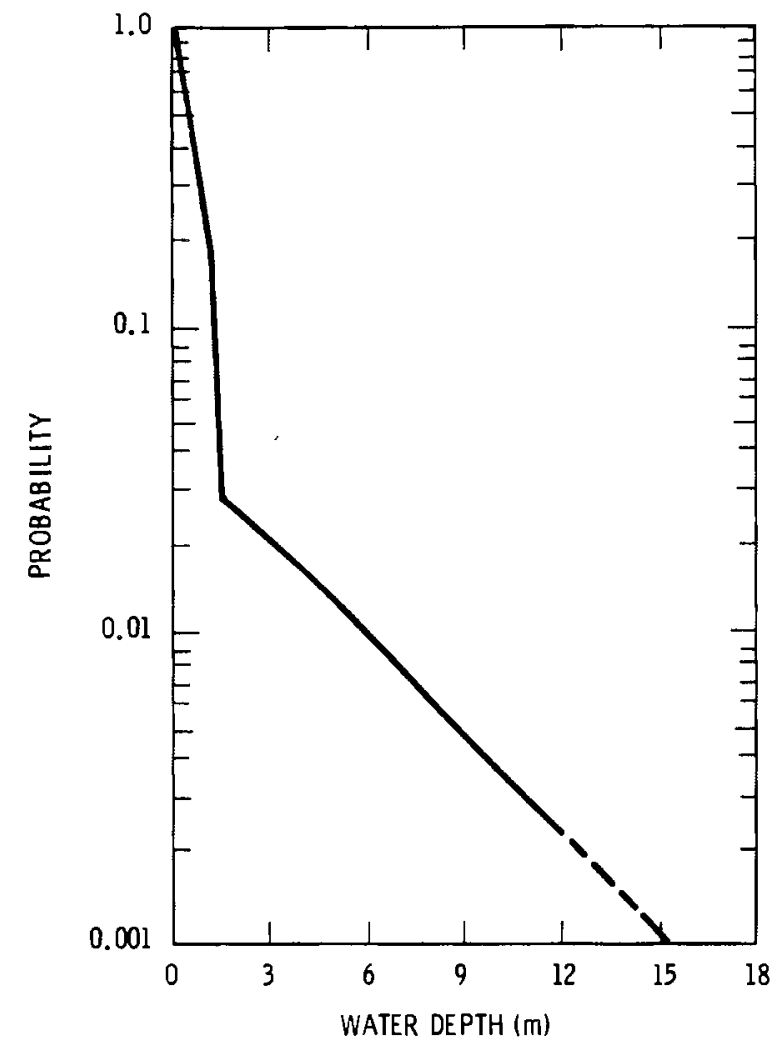

FIGURE C.8. Probability of Immersion at Depth Greater Than That Shown, Given Immersion

thus important to determine the probability of the closed wall trailer, or van being breached by the energy of the separate yellowcake containers that is created in an impact accident. According to information presented by Sandia Laboratories, the probability of a van being breached, given that a collision or overturn accident has occurred, is 0.06 (Clarke 1976, p. 48). This value is used for this event.

Drums Failed by Impact Forces (X7)

The results of tests on the Specifiction $17 \mathrm{H}$ drum suggest that these drums can survive an impact that is equivalent to a drop onto an unyielding surface from a height of 1.2 meters. This value, derived in Section C.3, is used as the failure threshold for the uranium ore concentrate drums. Data from Sandia Laboratories accident environment studies (Clarke 1976), presented in Figure C.9, 


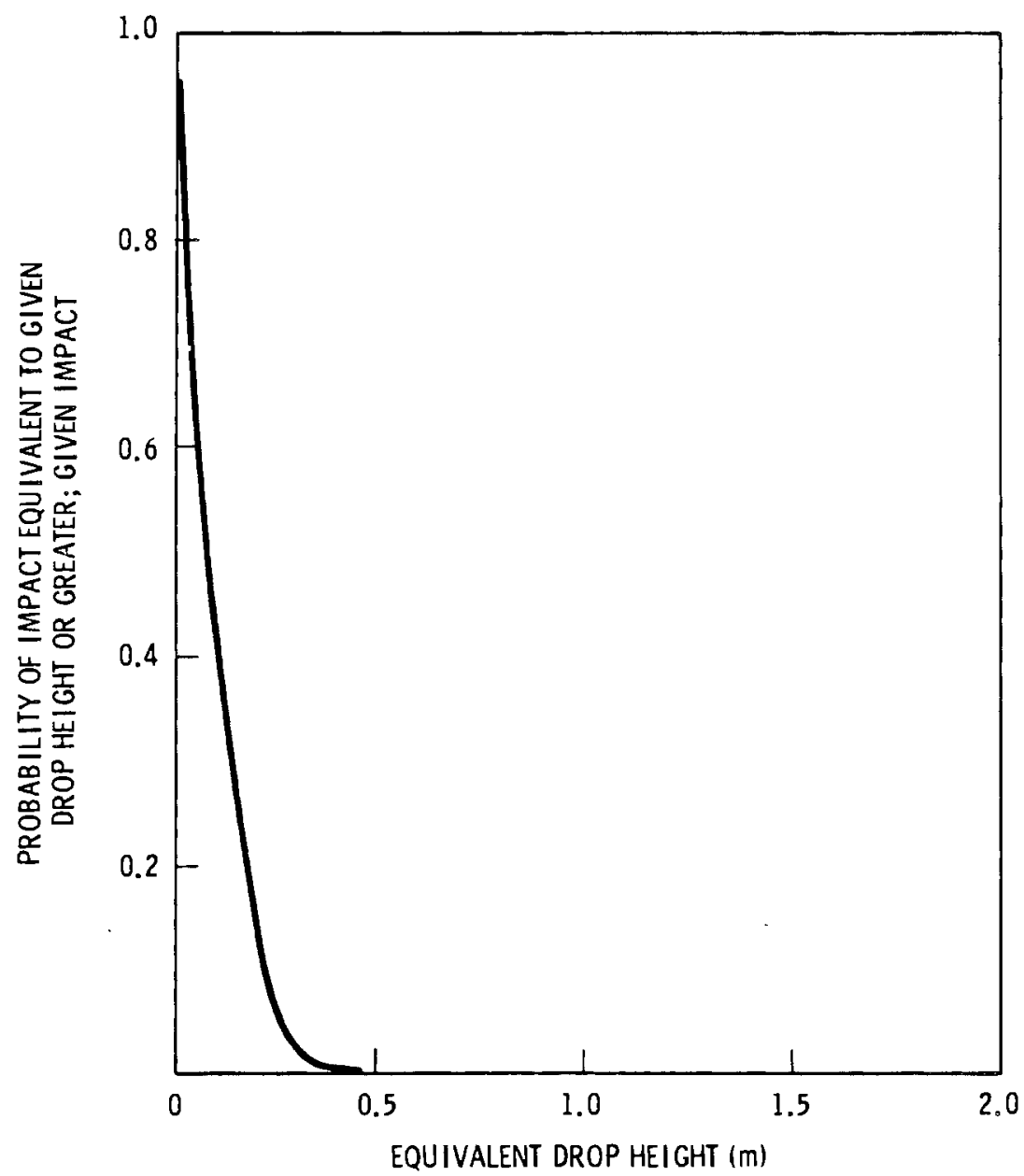

FIGURE C.9. Cumulative Distribution of Impact-Equivalent Drop Height, Given an Impact

shows that for a container of about $360 \mathrm{~kg}$, essentially a11 impacts experienced will be equivalent to a 0.5 meter drop or less. The likelihood of drum failure by impact is thus very sma11. Based on engineering judgement, a value of 0.01 will be used for this event.

Crush Forces Produced in Accident (X8)

Information from Sandia Laboratories (Clarke 1976) suggests that crush forces are produced in a11 impact accidents. The value used for this event is thus the same as for event $\times 5$, or 0.894 . 
Crush Forces Sufficient to Fail Drums (X9)

Crush forces are the result of inertial loadings on the container by other containers within the truck trailer. Result of structural analysis on the yellowcake drums, presented in Section C.2, shows that a crush force of approximately $9525 \mathrm{~kg}$ or a deceleration of over $3 \mathrm{~g}$ is required to fail the drums. Sandia information, reproduced in Figure C.10, indicates that this level of force or greater may be expected in about $15 \%$ of collision accidents. Therefore, a probability value of 0.15 is used for this event.

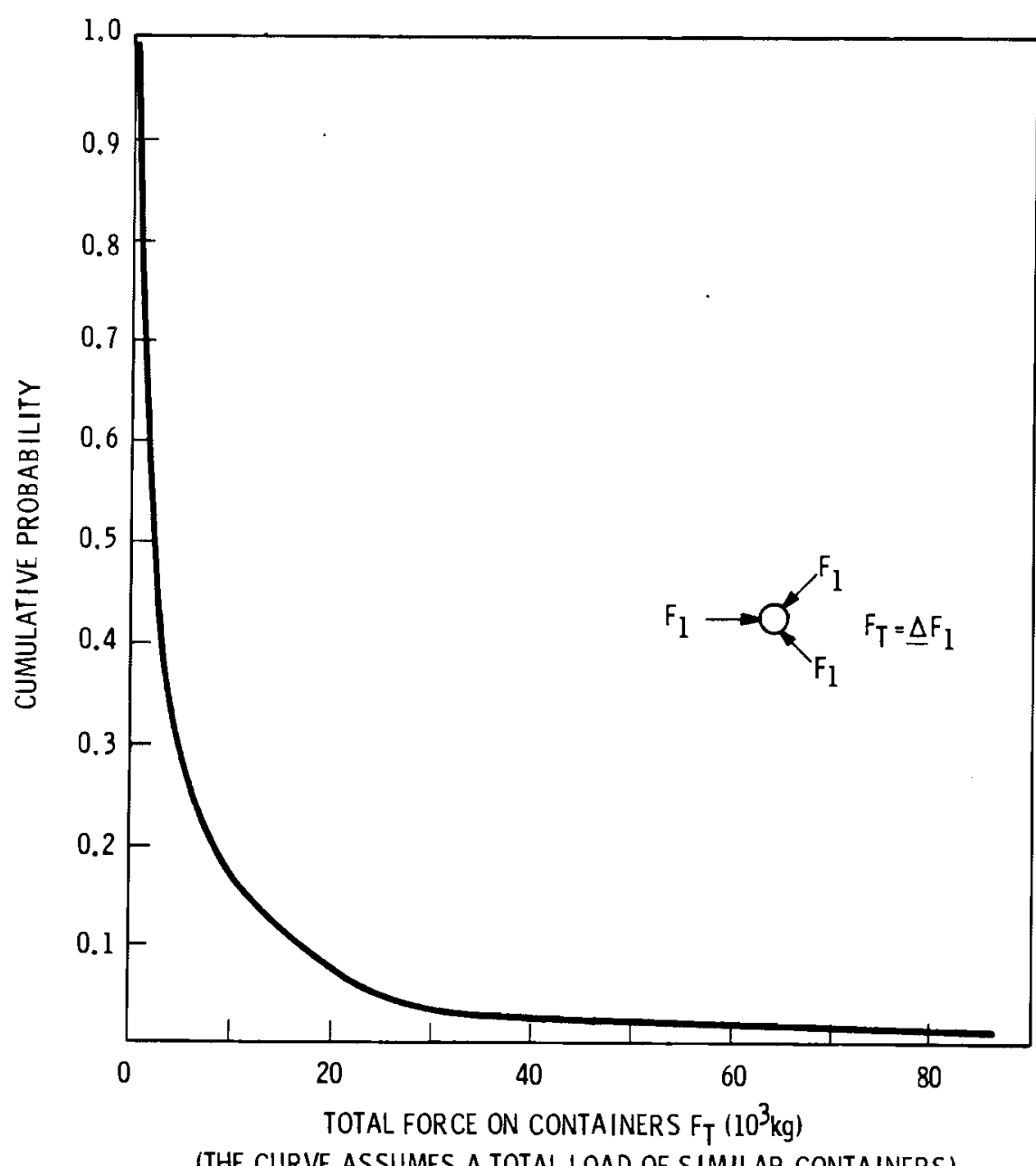

(THE CURVE ASSUMES A TOTAL LOAD OF SIMILAR CONTAINERS)

FIGURE C.10. Cumulative Distribution of Crush Forces Showing Probability of Encountering a Crush Environment More Severe Than Chosen Force if a Collision Occurs 
Drums Ejected from Van in Crush Accident (X10)

As explained in event $\times 6$, a release of material will present risks to the public only if it is allowed to escape the van. This event represents the probability of escape to the environment of a drum that has been failed by crush forces in an accident.

As in event $\times 6$, the probability of van breach given a collision accident is 0.06 . Accident information presented by Sandia shows that in all cases where a closed van was breached, the deceleration forces present were greater than $3 \mathrm{~g}$ and sufficient to fail the yellowcake drums (Clarke 1976, pp. 490, 59). The value used for this event is thus 0.06 . 


\section{REFERENCES}

Handbook of Tables for Applied Engineering Science. 1970. The Chemical Rubber Company.

Edling, D. A. and Griffin, J. F. 1975. Certification of ERDA Contractors' Packaging with Respect to Compliance with D0T Specification 7A Performance Requirements. Phase II Summary Report, MLM-2228.

Colton, J. D. and Emerson, R. E. 1978. Study of the Mechanics of a Transportation Accident Involving Natural Uranium Concentrate. NUREG/CR-0558, Nuclear Regulatory Commission, Washington, D.C.

Clarke, R. K. et al. 1976. Severities of Transportation Accidents. SLA-740001 , Sandia Laboratories, Albuquerque, New Mexico.

HEATING3 - An IBM 360 Heat Conduction Program. 1971. ORNL-TM-3208, (with HEATING4 updates), Oak Ridge National Laboratory, Oak Ridge, Tennessee.

ADINA, A Finite Element Program for Automatic Dynamic Incremental Nonlinear Analysis. 1976. Klaus-Jurgen Bathe.

Goldsmith, W. 1960. "Impact, the Theory and Physical Behavior of Colliding Solids."

Timoshenko, S. P. and Gere, J. M. 1961. Theory of Elastic Stability. 

APPENDIX D

ESTIMATED AIRBORNE RELEASE FRACTIONS 


\section{APPENDIX D}

\section{ESTIMATED AIRBORNE RELEASE FRACTIONS}

When a source material falls through moving air, a portion of the material will become airborne; Mishima (1976) includes two values for this entrainment. These were part of a series of four experiments conducted by dropping soil into a wind tunnel and measuring the mass of airborne soil. Although the soil particle size distributions may not exactly match those of yellowcake, the data is considered valid for dispersion values for a particulate such as yellowcake. In these experiments, the soil was injected with air and pumped into the top of a 2 foot square wind tunnel; samples were collected downstream. The amount of soil that became airborne was linear with the centerline air velocity, as seen in Figure D. 1 , where the results have been extrapolated to $18 \mathrm{~m} / \mathrm{sec}$. Table D.1 presents the values for specific wind speeds of the amount of a particulate release that is available for immediate airborne suspension.

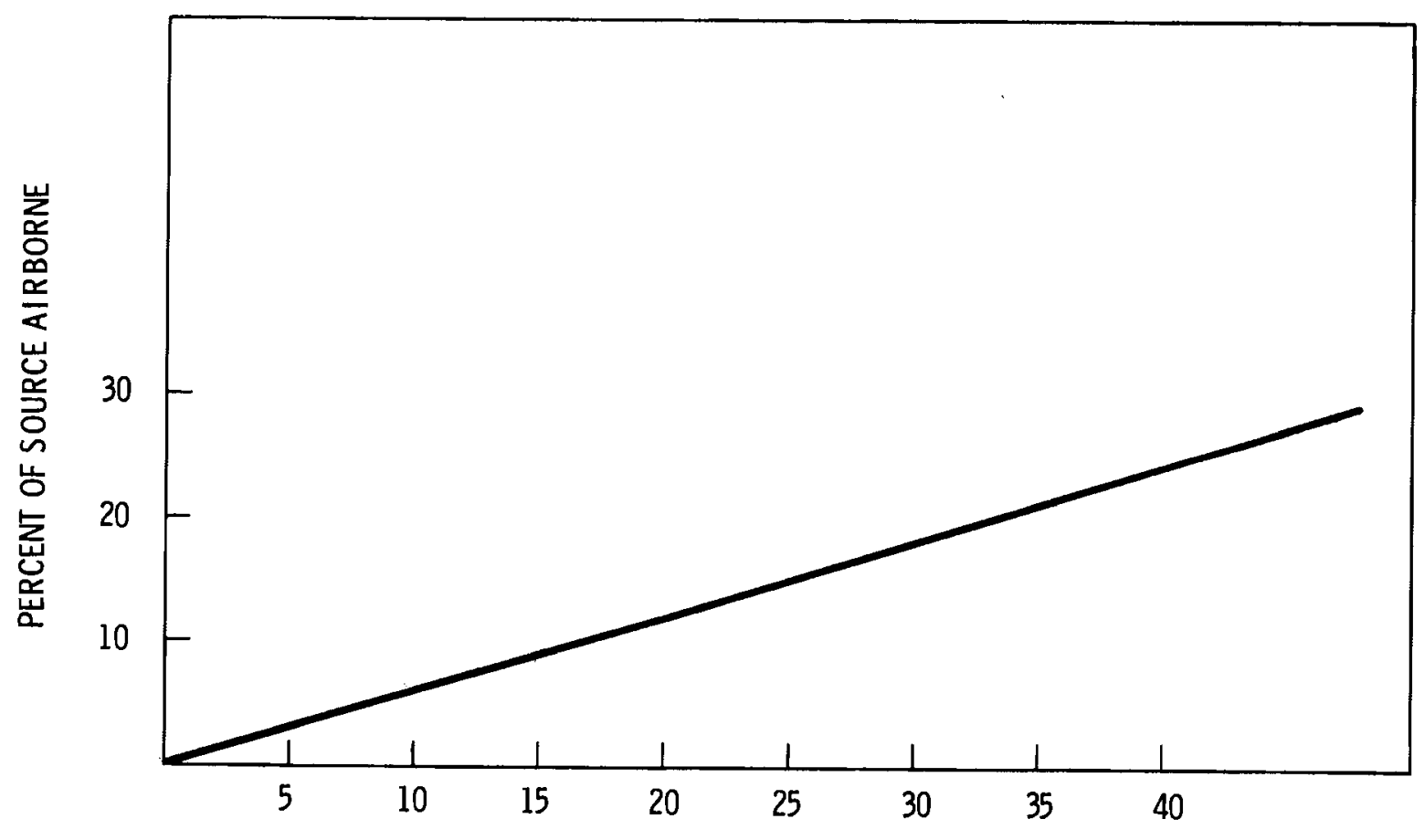

WIND SPEED, MPH

FIGURE D.1. Fraction of Source Potentially Airborne as a Function of Wind Speed $1 \mathrm{mph}=0.447 \mathrm{~m} / \mathrm{sec}$ 
TABLE D.1. Fraction of Source Potentially Airborne

\begin{tabular}{|c|c|c|}
\hline $\begin{array}{c}\text { Wind Speed } \\
\mathrm{m} / \mathrm{sec} \\
\end{array}$ & $\begin{array}{c}\text { Probability } \\
\text { of Encountering a } \\
\text { Particular Wind Speed }\end{array}$ & $\begin{array}{l}\text { Percent } \\
\text { Potentially } \\
\text { Airborne } \\
\end{array}$ \\
\hline 1 & 0.255 & 1.0 \\
\hline 3.5 & 0.508 & 5.0 \\
\hline 7 & 0.161 & 9.0 \\
\hline 10 & 0.052 & 13.0 \\
\hline 18 & 0.024 & 24.5 \\
\hline
\end{tabular}

Although no information is available to verify the results of the extrapolation to the higher wind speeds, the 10 and $18 \mathrm{~m} / \mathrm{sec}$ wind speeds are a very low probability occurrence (see Table D.l above), so the uncertainty of the extrapolation is balanced by the low frequency of events.

Resuspension of spilled material will also be a factor in an accident. Resuspension, the entrainment of particles from surfaces by aerodynamic forces, is dependent on many factors, including wind speed, particle size, the surface on which the particles are dispersed, weather conditions, and time after initial dispersion. Factors applicable to estimating particulate airborne by resuspension subsequent to a transportation accident have been generated in field and laboratory tests. Some of these have been compiled (Mishima 1976) and can be used to estimate airborne release. The following two methods of estimating resuspension releases were considered:

- A long-term resuspension rate of $1 \times 10^{-8} / \mathrm{sec}$ to $1 \times 10^{-10} / \mathrm{sec}$ has been observed for submicron particles deposited on prairie terrain at wind speeds of 1.3 to $20.8 \mathrm{~m} / \mathrm{sec}$ (Mishima 1976). This is a long-term resuspension rate, however, and does not necessarily reflect the higher rate of resuspension that could occur immediately after the material is dispersed.

- Other experiments report resuspension of $10 \%, 58 \%$, and $75 \%$ of source powders by air stresses in laboratory experiments. Release values for aerodynamic entrainment from freshly dispersed material on various surfaces for a 24 hour period are reported (Mishima 1976). These were the 
release fraction for sandy soil and vegetation covered sandy soil at wind speeds of $1.1 \mathrm{~m} / \mathrm{sec}$ and $8.9 \mathrm{~m} / \mathrm{sec}$. These values were assumed to be a direct function of wind speed and plotted as a straight line in Figure 0.2 , and extrapolated to $18 \mathrm{~m} / \mathrm{sec}$. This technique will give a conservative value when used in the safety analysis since, as seen in the plot, at the maximum wind speed the extrapolation gives a value greater than one. The fractional release will probably maximize at some point as indicated by the dotted line in the plot, but the data to estimate this are not available. The fractional releases used in this study, derived from Figure D.2, are listed in Table D.2.

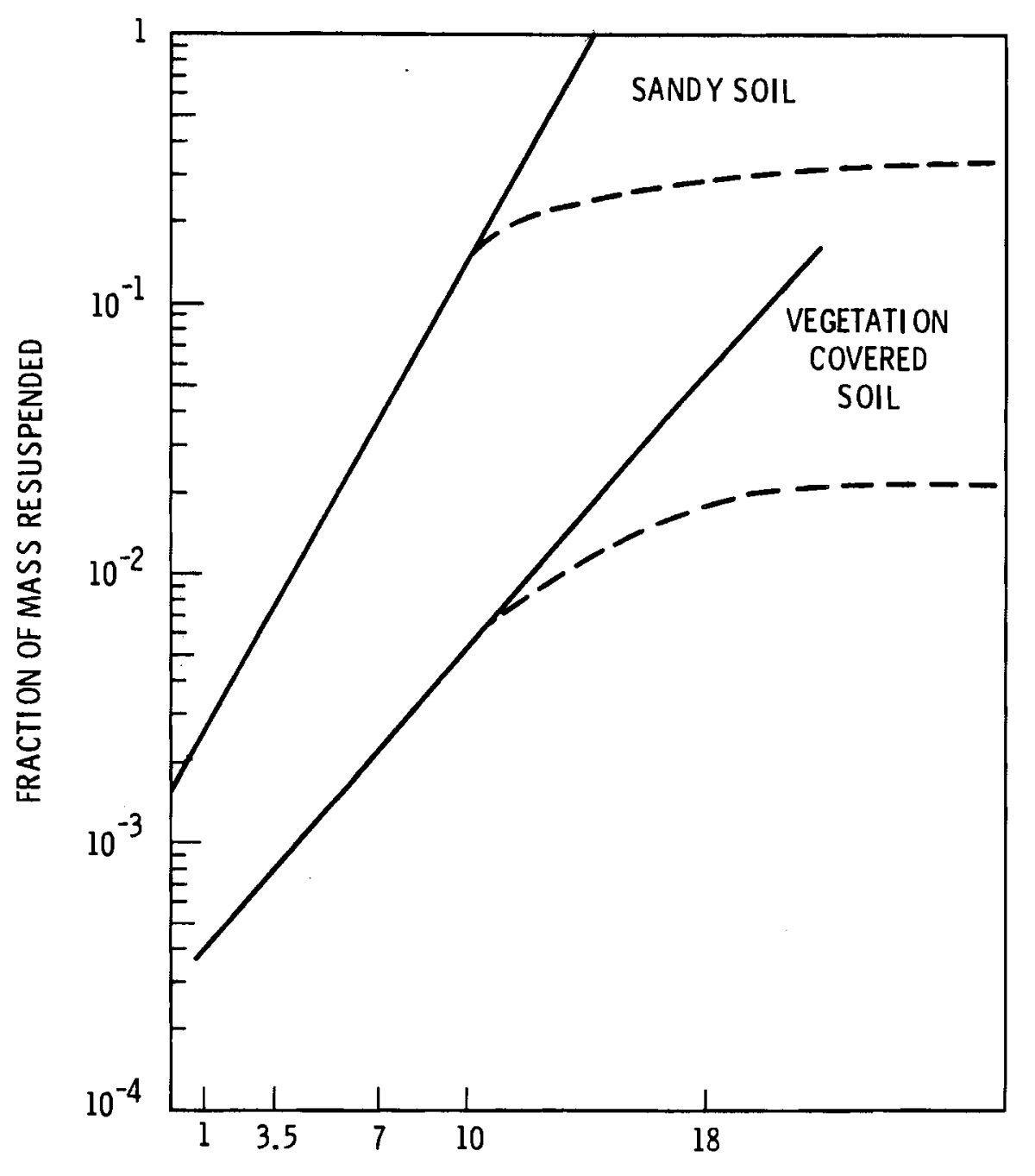

WIND SPEED, $\mathrm{m} / \mathrm{sec}$

FIGURE D.2. Fraction of Mass Resuspended from Two Surfaces, Freshly Dispersed $\mathrm{UO}_{2}, 24$-Hour Period Following Dispersal 
TABLE D.2. Fraction of Mass Resuspended from a Surface, Freshly Dispersed $\mathrm{UO}_{2}$ 24-Hour Period Following Dispersion

\begin{tabular}{|c|c|c|c|}
\hline \multirow{2}{*}{\multicolumn{2}{|c|}{$\begin{array}{c}\text { Wind Speed } \\
\mathrm{m} / \mathrm{sec}\end{array}$}} & \multicolumn{2}{|c|}{ Fractional Resuspended Release } \\
\hline & & Sandy Soil & $\begin{array}{c}\text { Vegetation } \\
\text { Covered Soi] }\end{array}$ \\
\hline & 1 & $2.4 \times 10^{-3}$ & $3.8 \times 10^{-4}$ \\
\hline 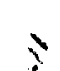 & 3.5 & $8.0 \times 10^{-3}$ & $8.0 \times 10^{-4}$ \\
\hline$\dot{m}$ & 7 & $3.9 \times 10^{-2}$ & $2.2 \times 10^{-3}$ \\
\hline & 10 & $1.5 \times 10^{-1}$ & $5.5 \times 10^{-3}$ \\
\hline & 18 & 1 & $5.7 \times 10^{-2}$ \\
\hline
\end{tabular}

For this study, a time period for anticipated releases was conservatively assumed to be 24 hours. It is likely, however, that a spill would be discovered and corrective action taken before this time to prevent further dispersal of material. In a spill of yellowcake resulting from a transportation accident, the spill was covered after about 13 hours had elapsed (Smith 1978).

In estimating the hazard from airborne releases, the inhalation potential of the source material is also important. The size of the particles in the releases provide an index to the hazard. Those less than 10 microns in diameter can be inhaled and released in the bronchial system. The particle size distribution for yellowcake is presented in Appendix B. On the average, about 25\% of yellowcake particles are less than 10 microns in diameter.

IMPACT

In the release sequence where the drums are failed by impact forces, the van is breached in an impact accident and intact drums escape. The drums fail as they hit the ground. Failure of drums inside the van has been found to be more realistically modeled by crush force. To determine the amount of material released, it is necessary to know the number of containers that are ejected from the van. In the event that a truck trailer or van is breached, Sandia Laboratories estimates that about one third of the containers will be ejected ( $C l a r k e$ 1976, p.48). Thus, in this release sequence, about 17 drums escape the van. It is assumed that about $30 \%$ of the contents of each ejected drum will be spilled as the drum fails. 
The yellowcake pours from the drums after the drums are at the ground surface. In this type of bulk flow incident, only a small part of the material will be mixed with air sufficiently to induce airborne dispersion. This is estimated as about $10 \%$ of the mass, with only a fraction of this in the respirable size range.

The immediate airborne release is estimated by this formulation: 17 drums $\times 363 \mathrm{~kg} /$ drum $\times 30 \%$ released $\times 10 \%$ mixed with air $\times$ respirable fraction $\times$ fraction immediately airborne. This calculation is made in Table D.3.

The 24-hour resuspension factors were considered appropriate to use to calculate initial dispersion: the respirable size powder was considered in piles and readily subjected to resuspension forces. The possibility of the $100 \%$ resuspension indicated at $18 \mathrm{~m} / \mathrm{sec}$ is highly unlikely.

\section{TABLE D.3. Release Fraction Calculations for Impact Accident}

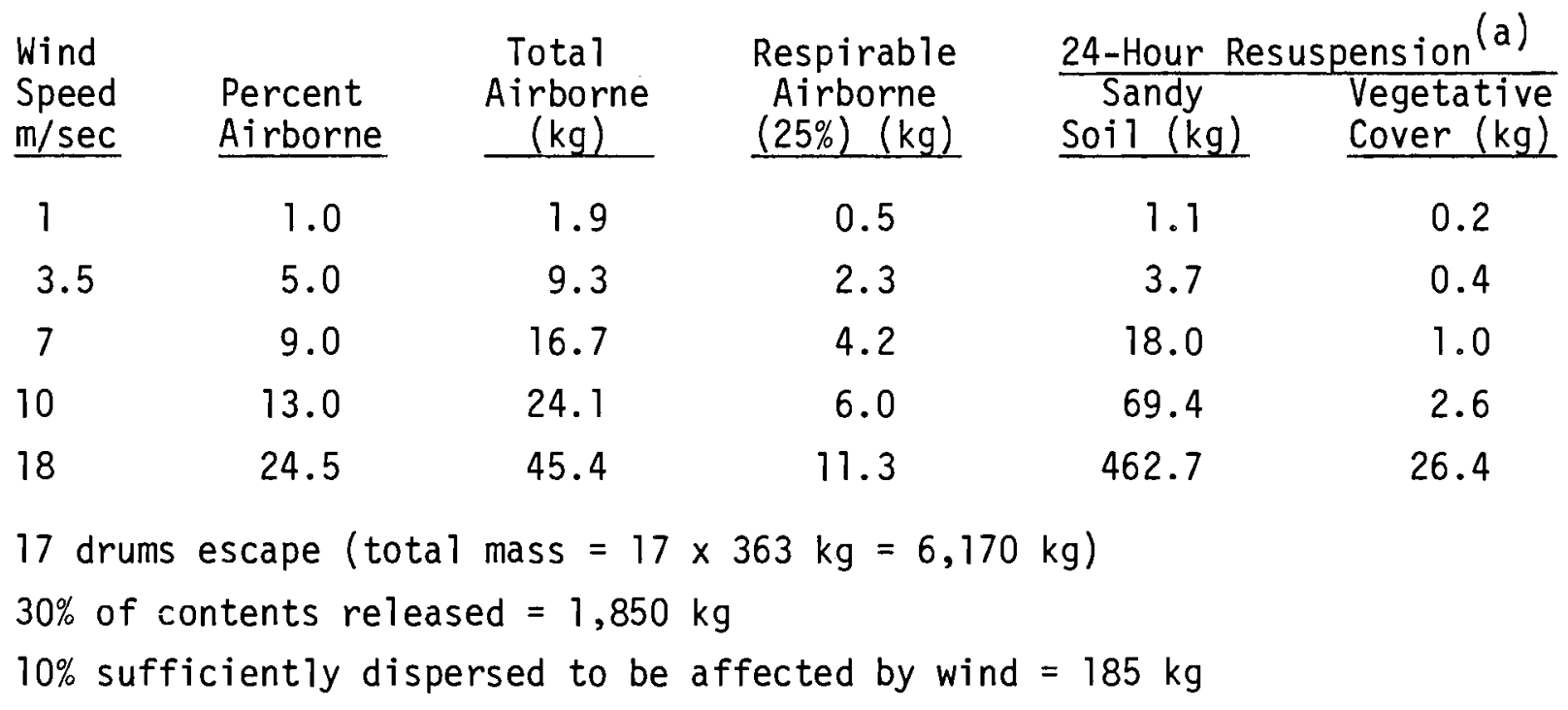

(a) Based on the respirable content of the $30 \%$ mass released.

CRUSH

In the release sequence where the drums are failed by crush forces, failed drums escape the van. The number of failed drums involved in this sequence is determined from Appendix C. About $80 \%$ of the drums wi11 fail in the postulated 
crush accident. However, as in the impact accident sequence, only one third of the trailer contents escape, or 17 drums. It is conservatively assumed that al1 drums that escape have been previously failed by inertial crush forces. Data from a yellowcake transportation accident show that these failed drums spilled about $50 \%$ of their contents as they traveled to and hit the ground (Smith 1978). This same value is used for the purposes of this study.

The containers also spill powder in the van itself. This powder fills the truck van with $100 \mathrm{mg} / \mathrm{m}^{3}$ of suspended powder (Selby 1975). The entire volume of the truck is $35 \mathrm{~m}^{3}$ and the volume of the drums is $13.0 \mathrm{~m}^{3}$, leaving a free volume of $22 \mathrm{~m}^{3}$. Thus, $2.2 \mathrm{~g}$ can fill the truck, a value that is negligible compared to other releases.

The airborne drums tumble through the air, and loose powder subsequently falls to the ground. The powder is entrained in air, more than in the impact release sequence. It is estimated that $50 \%$ of the powder flow is intermingled with the air and subjected to immediate airborne release. This calculation is then: 17 drums $\times 363 \mathrm{~kg} /$ drum $\times 50 \%$ released $\times 50 \%$ mixed with air $\times$ respirable fraction $x$ fraction immediately airborne. This calculation is shown in Table D.4.

TABLE D.4. Release Fraction Calculations for Crush Accident

\begin{tabular}{|c|c|c|c|c|}
\hline $\begin{array}{l}\text { Wind } \\
\text { Speed } \\
\mathrm{m} / \mathrm{sec} \\
\end{array}$ & $\begin{array}{l}\text { Percent } \\
\text { Airborne }\end{array}$ & $\begin{array}{l}\text { Total } \\
\text { Airborne } \\
(\mathrm{kg}) \\
\end{array}$ & $\begin{array}{l}\text { Respirable } \\
\text { Airborne } \\
(25 \%)(\mathrm{kg}) \\
\end{array}$ & $\begin{array}{c}\text { Long Term } \\
\text { Resuspension }(a) \\
(\mathrm{kg} / \mathrm{sec})\end{array}$ \\
\hline 1 & 1.0 & 15.4 & 3.9 & $3.09 \times 10^{-5}$ \\
\hline 3.5 & 5.0 & 77.2 & 19.3 & $3.09 \times 10^{-5}$ \\
\hline 7 & 9.0 & 138.9 & 34.7 & $3.09 \times 10^{-5}$ \\
\hline 10 & 13.0 & 200.6 & 50.2 & $3.09 \times 10^{-5}$ \\
\hline 18 & 24.5 & 378.0 & 94.5 & $3.09 \times 10^{-5}$ \\
\hline
\end{tabular}

(a) Based on the $50 \%$ contents released. 
The long term resuspension rate of $1 \times 10^{-8} / \mathrm{sec}$ was considered appropriate to use--most of the dispersable particles were removed during the fall. The remaining powder would be distributed on the surface in a fashion where resuspension would be low. 


\section{REFERENCES}

Clarke, R. K. et. al. 1976. Severities of Transportation Accidents. SLA-740001 , Sandia Laboratories, A1burquerque, New Mexico.

Mishima, J. 1976. "Potential Aerosol Generation Mechanisms from Damaged Packages." IAEA-SR 10/15, from Transport Packaging for Radioactive Material, Proceedings of a seminar, Vienna, Austria.

Selby, J. M., et. a1. 1975 Considerations in the Assessment of the Consequences of Effluents from Mixed Oxide Fuel Fabrication Plants. BNWL-1697, Rev. 1, Battelle, Pacific Northwest Laboratories, Richland, Washington.

Smith, M. L. 1978. "Health Physics Aspects of a Truck Accident Involving a Yellowcake Spi11." Exxon Mineral Company. 
PNL -3463

TTC -0146

UC-71

\section{DISTRIBUTION}

No. of

Copies

OFFSITE

Tom Alexander

Department of Energy

Office of Technology Impacts

EV-212, MS-46065

Forrestal Bldg.

Washington, DC 20585

G. C. Allen, Jr.

Sandia National Laboratories

Division 4552

Albuquerque, NM 87185

John Allen

Materials Transportation Bureau

400 Seventh St., SW

Washington, DC 20590

T. Anderson

Department of Energy

Mai1 Stop B/107

Washington, DC 20545

A. L. Babb

Department of Nuclear Engineering

Benson $\mathrm{Hall}$

University of Washington

Seattle, WA 98195

Hubert Baker

E. I. DuPont de Nemours \& Co.

Savannah River Laboratory

Aiken, SC 29801

L. Benner

National Transportation Safety Board

Department of Transportation

Washington, DC 20594

K. Carlson

DOE Albuquerque Operations

Office

Albuquerque, NM 87115
No. of

$\underline{\text { Copies }}$

J. M. Cece

DOE/ESED

M/S EV-132, E-201

Washington, DC 20545

A. A. Churm

Chicago Patent Group

DOE Chicago Operations Office

9800 South Cass Avenue

Argonne, IL 50439

C. Comar

Electric Power Research Inst.

P. 0. Box 10412

Palo Alto, CA 94304

J. S. Corbett

ChemNuclear Systems, Inc.

P. 0. Box 1866

Bellevue, WA 98009

J. Counts

DOE/ESED

M/S EV-13, E-201

Washington, DC 20545

M. J. Cullingford

Nuclear Regulatory Commission

Washington, DC 20555

N. Darmstader

American Trucking Association

1616 P Street, NW

Washington, DC 20036

27 DOE Technical Information Center

D. A. Edling

Mound Laboratory

P. 0. Box 32

Miamisburg, $\mathrm{OH} 45342$ 
No. of

Copies

F. P. Falci

Department of Energy

Mail Stop B-107

Washington, DC 20545

Transportation Dept.

Southern Interstate Nuclear Board

One Exchange Place, Suite 1230

Atlanta, GA 30341

J. T. Foley

Sandia National Laboratories

Division 5522

Albuquerque, NM 87185

R. F. Garrison

DOE

Mai1 Stop B/107

Washington, DC 20545

M. Gordon

Atomic Industrial Forum

7101 Wisconsin Avenue

Washington, DC 20014

0. P. Gormley

Department of Energy

Mai1 Stop B/107

Washington, DC 20545

Brad Holloman

Office of Technology Assessment

U.S. Congress

Washington, DC 20510

Alexandria Holufowich

NUCLEONICS WEEK

1221 Avenue of the Americas

New York, NY 10020

R. M. Jefferson

Sandia National Laboratories

Dept. 4550

Attn: TTC Master File (1)

A1buquerque, NM 87185
No. of

Copies

B. Jody

Davis Transport, Inc.

P. 0. Box 1139

Paducah, KY 42001

B. Jost

Mail Stop 18

California Energy Commission

1111 Howe Avenue

Sacramento, CA 95825

R. A. Koynenburg University of California

Lawrence Livermore Laboratories

P. 0. Box 808

Livermore, CA 94551

R. W. Lambert

General Electric

175 Curtner Ave.

San Jose, CA 95125

M. J. Lawrence

Department of Energy

Mai1 Stop B/107

Washington, DC 20545

R. Y. Lowrey

DOE Albuquerque Operations Office

Albuquerque, NM 87115

R. E. Luna

Attn: E. W. Shepherd

Sandia National Laboratories

Division 4551

Albuquerque, NM 87185

J. C. Mataro

NRC

Mai1 Stop NL5650

Washington, DC 20555

C. H. Mayer

Tri-State Motor Transit Co., Inc.

P. 0. Box 113

Jopl in, MO 64801 
No. of

Copies

J. D. McClure

Sandia National Laboratories

Division 4551

Albuquerque, NM 87185

C. McDonald

Nuclear Regulatory Commission

Washington, DC 20555

Susan Metzler

Sys tem Communications

N.E. Utilities

P. 0. Box 270

Hartford, CT 06101

R. M. Moser

DOE Chicago Operations Office 9800 South Cass Avenue

Argonne, IL 60439

D. Okrent

Department of Engineering and Applied Science

University of California

Los Angeles, CA 90024

R. W. Peterson

Battelle Memorial Institute

Office of Nuclear Waste

Isolation

505 King Avenue

Columbus, $\mathrm{OH} 43201$

R. B. Pope

Sandia National Laboratories

Division 4552

Albuquerque, NM 87185

J. Pyle

Kerr-McGee Nuclear

Oklahoma City, OK 73125

Prof. Norman C. Rasmussen

Massachusetts Institute of Technology

Cambridge, MA 02139
No. of

Copies

R. R. Rawl

Office of Hazardous Materials

Regulations

4007 th Street, SW

Washington, DC 20590

J. L. Russell

Office of Radiation Programs

AW-459, EPA

401 M. Street, SW

Washington, DC 20460

E. Rutenkroger

Tri-State Motor Transit Co., Inc. P. 0. Box 113

Jopl in, M0 64801

L. D. Santman

Materials Transportation Bureau

Department of Transportation

2100 Second Street, SW

Washington, DC 20590

A. L. Schmeig

National Transportation Safety Board

Department of Transportation

Washington, DC 20594

H. G. Shealy

Bureau of Radiological Health

South Carolina Department of Health and Environmental Control

Columbia, SC 29405

J. A. Sisler

Department of Energy

Mai 1 Stop/B107

Washington, DC 20545

W. R. Teer

Transnuclear Inc.

One N. Broadway

White Plains, NY 10601 
No. of

Copies

F. Trimmer

Salt Creek Freightways

Casper, WY 82601

(5) TTC Library

Sandia National Laboratories

Dept. 4551

Albuquerque, NM 87185

Henry Walter

Environmental and Safety

Engineering Division

U.S. Department of Energy

Washington, DC 20545

R. F. Williams

Electrical Power Research Inst.

P. 0. Box 10412

Palo Alto, CA 94304

E. L. WiTmot

Sandia National Laboratories

Division 4551

Albuquerque, NM 87185

Nuclear Safety Research

Association

Room 1037, National Press

Building

14th and F St., NW

Washington, DC 20004

G. Yates

Allied Chemical

Metropolis, IL 62960

H. R. Yoshimura

Sandia National Laboratories

Division 4553

Albuquerque, NM 87185
No. of

Copies

ONSITE

DOE-Richland Operations Office

P. A. Craig

J. M. Peterson

H. E. Ransom

J. J. Schreiber

M. W. Shupe

Pacific Northwest Laboratory

J. M. Alzheimer

W. B. Andrews

W. J. Bailey

M. J. Budden

N. M. Burleigh (5)

T. D. Chikalia

J. G. DeSteese

R. M. Fleischman

A. L. Franklin

J. R. Friley

C. A. Geffen (10)

M. R. Kreiter

J. Mishima

B. Napier

R. E. Rhoads

K. J. Schneider

S. L. Sutter

L. D. Williams

Technical Information Ma (5)

Publishing Coordination (2)

Battel 1e-Human Affairs Research Center

C. R. Schuller

A. H. Schilling 